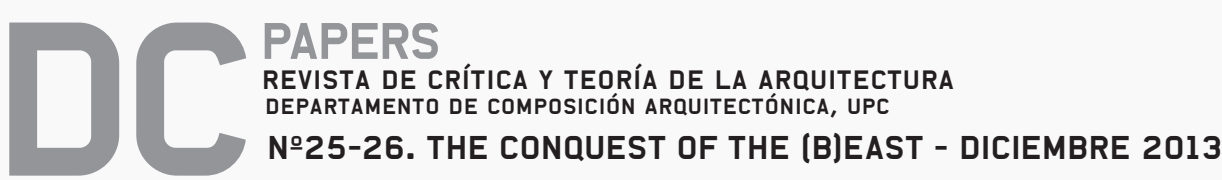

AUTOR: Joaquín Sanmartín.

UNIVERSIDAD: Instituto Universitario del Próximo Oriente Antiguo (IPOA), Universidad de Barcelona.

BREVE bIOGRAFÍA: Catedrático en el Departamento de Filología Semítica y Director del Instituto Universitario de Estudios del Próximo Oriente Antiguo y coordinador del Grupo Consolidado de Calidad LINGORIE (Lingüística Oriental), Universitat de Barcelona. Sus líneas de investigación son la Filología Semítica Comparada, y la morfología y lexicografía de las lenguas paleosemíticas y semíticas medias (especialmente acadio, ugarítico, fenicio, hebreo). Ha dedicado su atención a los aspectos culturales del Próximo Oriente Antiguo (religión, sociedad y economía) y publicado más de 200 títulos entre artículos científicos y libros, entre ellos la edición, traducción y estudio de la Epopeya de Gilgamě̌, Rey de Uruk. Es coautor (junto con M. Dietrich y O. Loretz) de los Keilalphabetische Texte aus Ugarit y (con G. Del Olmo) del Dictionary of the Ugaritic Language in the Alphabetic Tradition.

TÍTULO: Babilonia, ida y vuelta. Del rey arquitecto al arquitecto rey.

IITLE: Babylon, there and back. From the Architect King to the King Architect.

RESUMEN: Los (pocos) reyes-arquitecto mesopotámicos que - para acercarse a los dioses- recurrieron al signo DINGIR "estrella" coinciden en un vértice con los (muchos) arquitectos-rey del (post)modernismo: su vocación estelar. El star system de unos y de otros, reyes-arquitecto o arquitectos-rey, tiende sus puentes a través de tres mil y pico de años de historia.

ABSTRACT: The (few) Mesopotamian architect-kings who -approaching to gods-used the sign DINGIR "star" happen to meet with the (many) king-architects of the (post)modernism in one point: his stellar vocation. The star system of ones and others, architect-kings or king-architects, tend bridges across more than three thousand years of history.

PALABRAS CLAVE: poder, arquitectura, rey, símbolo, star system.

KEYWORDS: Power, Architecture, King, simbol, star system.

CONTACTO: jsanmartin@ub.edu 


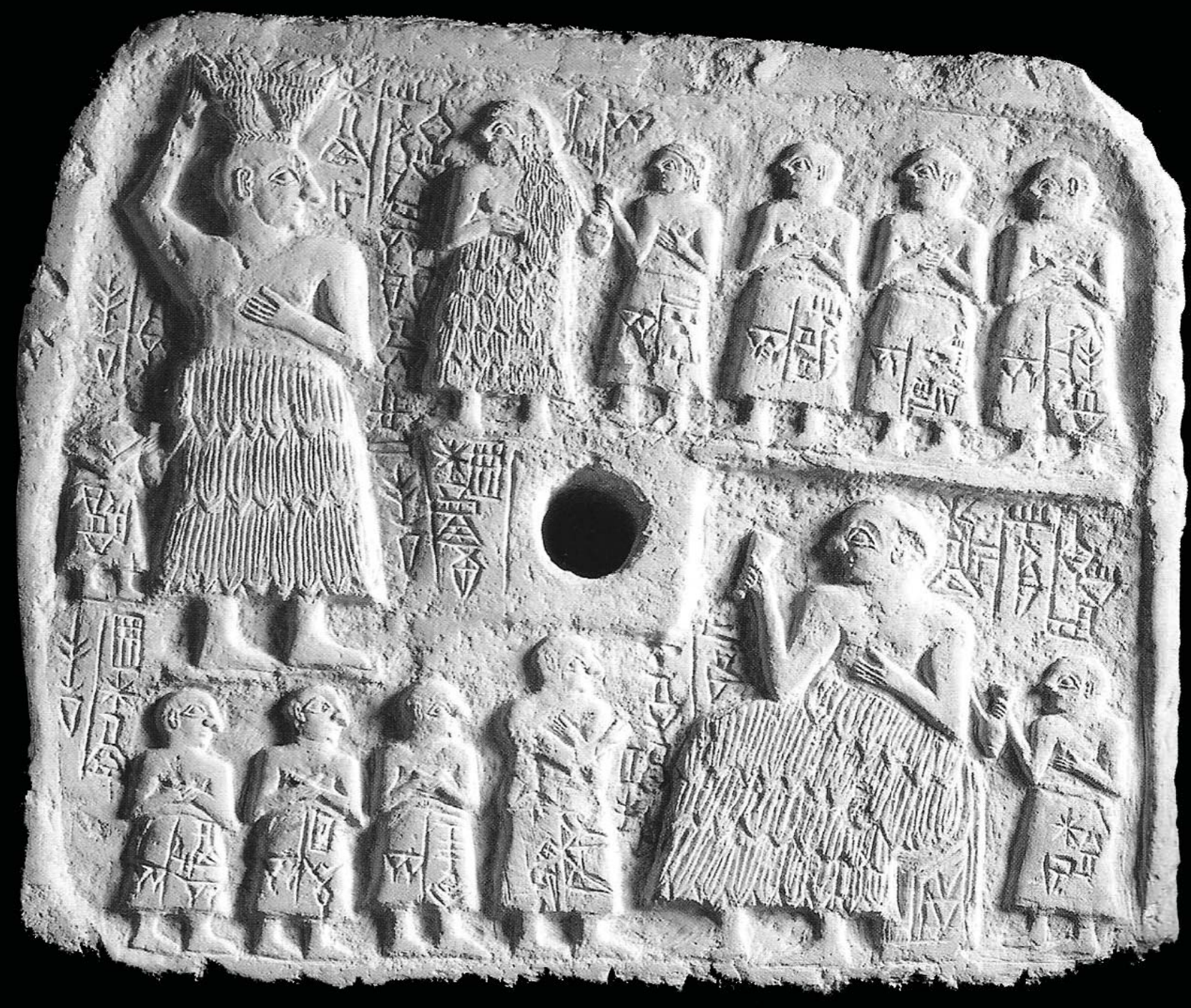




\section{BABILONIA, IDA Y VUELTA. DEL REY ARQUITECTO AL ARQUITECTO REY}

Joaquín Sanmartín

\section{URUK (DE LA MANO DE GILGAMESH)}

"Queda claro que el hombre, junto con las maneras monumentalística y anticuaria de contemplar el pasado, necesita a menudo una tercera manera: la crítica: y, desde luego, también ella al servicio de la vida" ${ }^{\mathrm{I}}$

Los dos viajeros venían de muy lejos: De más allá del fin del mundo, donde -en un limbo existencial-vivía el único mortal convertido en inmortal por un desajuste en la disciplina de voto del parlamento divino. El viejo les había aconsejado emprender el retorno a la lejana Uruk. Uno de los viajeros era un personaje de estatura más que notable cuyos andrajos no conseguían esconder ciertos restos de nobleza, casi diríase de divinidad. El otro avanzaba a su lado con los andares vacilantes del marino, o del barquero acostumbrado al equilibrio difícil en el esquife.

Era mediodía y apretaba el sol en lo que luego otros llamarían Al-'Trāq. Venían del oriente - en realidad: de más allá del oriente, y bajaban a buen paso hacia la marisma en que se recogían los dos ríos del mundo para volverse Mar Inferior. Ya mucho antes de avistar la ciudad ("la Ciudad") adivinaron su cercanía. El humo de decenas de miles de fuegos domésticos y de los talleres en que se refundían bronces, platas y oros se confundía con el polvo rojizo levantado desde los caminos, plazas y eras; un manto plomizo cubría la ciudad aún invisible. Luego llegaron los olores de los corrales exteriores en que se apelotonaban multitudes de ovejas, cabras y asnos. Oyeron el bramido de los bueyes que araban las alargadas parcelas y, luego, los golpes de pala de los jornaleros que removían las huertas bajo millones de palmeras. No era fácil acercarse a la ciudad porque estaba plantada en la marisma y rodeada de una red infinita de canales, acequias y zanjas de drenaje, pero uno de los dos personajes de esta historia -el gigantón-se sabía bien las sendas por haberlas recorrido mil veces cuando perseguía a las mozas del lugar para arrinconarlas en el cañaveral o hacía deporte con sus amigotes de palacio:

El superhombre andrajoso y su acompañante no eran otros que el rey expatriado Gilgamesh - "pastor de Uruk" y "guía del tropel de gentes"- ${ }^{2}$ y un barquero llamado Ur-Shanabi. Ambos parecían descolocados: El barquero porque llevaba muchos días pisando polvo, y Gilgamesh porque volvía a su ciudad tan mortal y tan fracasado como cuando partió para buscar lo inencontrable: La vida eterna.

Detrás de los carrizales que ocultaban el último canal tuvo lugar la epifanía de la Ciudad. La Uruk inamovible, enorme, luminosa, rodeada de los brazos solemnes del Éufrates, presidida por una torre escalonada cuya cima, descanso de los dioses, sobresalía de la neblina urbana. El caminante vencido se metamorfoseó en lo que nunca había dejado de ser: Gilgamesh, rey arquitecto de Uruk, descrito ya en la obertura de su Epopeya. Detrás quedaron las vanas hazañas del Bosque de los
I.

F. Nietzsche, Vom Nutzen und Nachteil der Historie für das Leben, Werke in drei Bänden, herausgegeben von K. Schlechta, vol. I, München I969.

2.

Gilgamesh, Tablilla I, lin. 63-72; J. Sanmartín, Epopeya de Gilgamesh, rey de Uruk, Madrid 22010, p. 93 y s. 
La ciudad de Uruk estaba rodeada de una muralla de unos nueve kilómetros de perímetro, salpicada de torres, que todavía es perceptible en la actualidad; la técnica de edificación permite fecharla en la época predinástica. Esta fortificación era circular y doble. Constaba de un muro exterior, sin torres, y de un muro interior de unos cinco metros de ancho, reforzado con pilastras que se transformaron con el tiempo en más de novecientas torres semicirculares. El espacio encerrado por tal muralla no estuvo nunca completamente edificado, y buena parte de los más de cinco kilómetros cuadrados de terreno se dedicaba a corrales, en los que podían refugiarse los ganados en caso de peligro, así como los habitantes de las cercanías. De ahí, probablemente, el sobrenombre de "Uruk, el Corral". Se connota, evidentemente, la idea de la ciudad sede del reypastor y refugio de sus habitantes.

4.

El E'Ana "casa del dios Anu" era un complejo constituidopor el templo del dios celeste Anu "Cielo", el de la diosa Ishtar y otros templos y edificios anejos. Poseía también una ziqqurāt o pirámide monumental escalonada.

5 .

Shar es el valor aritmético "3.600", es decir "60 x 60 ". Para los babilonios, usuarios del sistema sexagesimal, sesenta veces sesenta connotaba lo enorme, lo inabarcable: se empleaba especialmente con referencia a grandes extensiones o a cantidades inconmensurables.

6.

Se refiere a las zanjas de la que se extraía la arcilla casi lista para fabricar cerámica o ladrillos y que. debido a la altura de la capa freática, se encontraban siempre húmedas.
Cedros; las manos tentadoras de Ishtar; la sombra de su Enkidu; el viaje por la senda del Sol hacia la morada de Uta-Napishti, el viejo inmortal; el desengaño de saberse candidato a cadáver. ¿No era él Gilgamesh, el pastor de su Giudad? La pinza existencial se cerraba: Todo comenzó en Uruk, y todo terminaba en esa Uruk que él había levantado. Consummatum est! Nada se había perdido porque la Giudad Eterna cantaría por siempre las glorias de su arquitecto.

El que vio lo más hondo, los cimientos del País;

$(\ldots \ldots)$

Sabio en todos los campos: Gilgamesh:

el que vio lo más hondo, los cimientos del País;

$(\ldots \ldots \ldots)$

El sabio perfecto que lo entendió todo.

Vio lo secreto y descubrió lo escondido:

Nos trajo noticias de antes del Diluvio.

Volvió de un largo camino;

estaba rendido pero en paz, y grabó en una piedra todos sus trabajos.

Mandó construir la muralla de Uruk, el Corral, ${ }^{3}$

y el santo E'ana, ${ }^{4}$ tesoro radiante.

“ Contempla sus muros como trazados a cordel!

¡Mira sus contrafuertes, que nadie imitará!

¡Toma la escalera que lleva alli desde siempre!

¡Acércate al E'ana -la morada de Ishtar-

que no hay rey futuro, ni nadie, que lo imite!

¡Súbete a la muralla de Uruk, paséate por ella;

examina los fundamentos, fíate en el enladrillado!

¡A ver si esos muros no son de ladrillo cocido;

y si sus cimientos no los echaron los Siete Sabios!

Un shar ${ }^{5}$ es población,

un shar es huerta,

un shar, pozas de arcilla, ${ }^{6}$

medio shar, templo de Ishtar:

tres shares y medio encierra en sí Uruk.

(Gilgamesh, Tablilla I, lin. I-24, XI:324-328)7

El regreso del prófugo Gilgamesh a su ciudad es también su resurrección como rey. $\mathrm{Y}$ es importante recalcar que no son sus funciones sagradas o pastorales -ambas ciertamente esenciales de la realeza- sino la de constructor-arquitecto la que recompone su identidad perdida.

Ante él se alza una muralla, en la que se abre una de las enormes puertas fortificadas y flanqueadas de torres. Gilgamesh sabe que, si sube a esa muralla o escala una torre, se extenderá ante él todo el indescriptible panorama de su Uruk. En lugar destacado, la mole blanca, resplandeciente del domicilio del celeste dios An y de su virginal y pendenciera "hija", la diosa Inanna. La ciudad es una isla enorme de ladrillo plantada en la marisma, junto al río, al margen de la estepa; una especie de arca diluviana gigante, de ciudad flotante, de portaaviones varado en el paisaje como el de Hans Hollein en el MMA. A su alrededor, la Nada; en su interior, el 


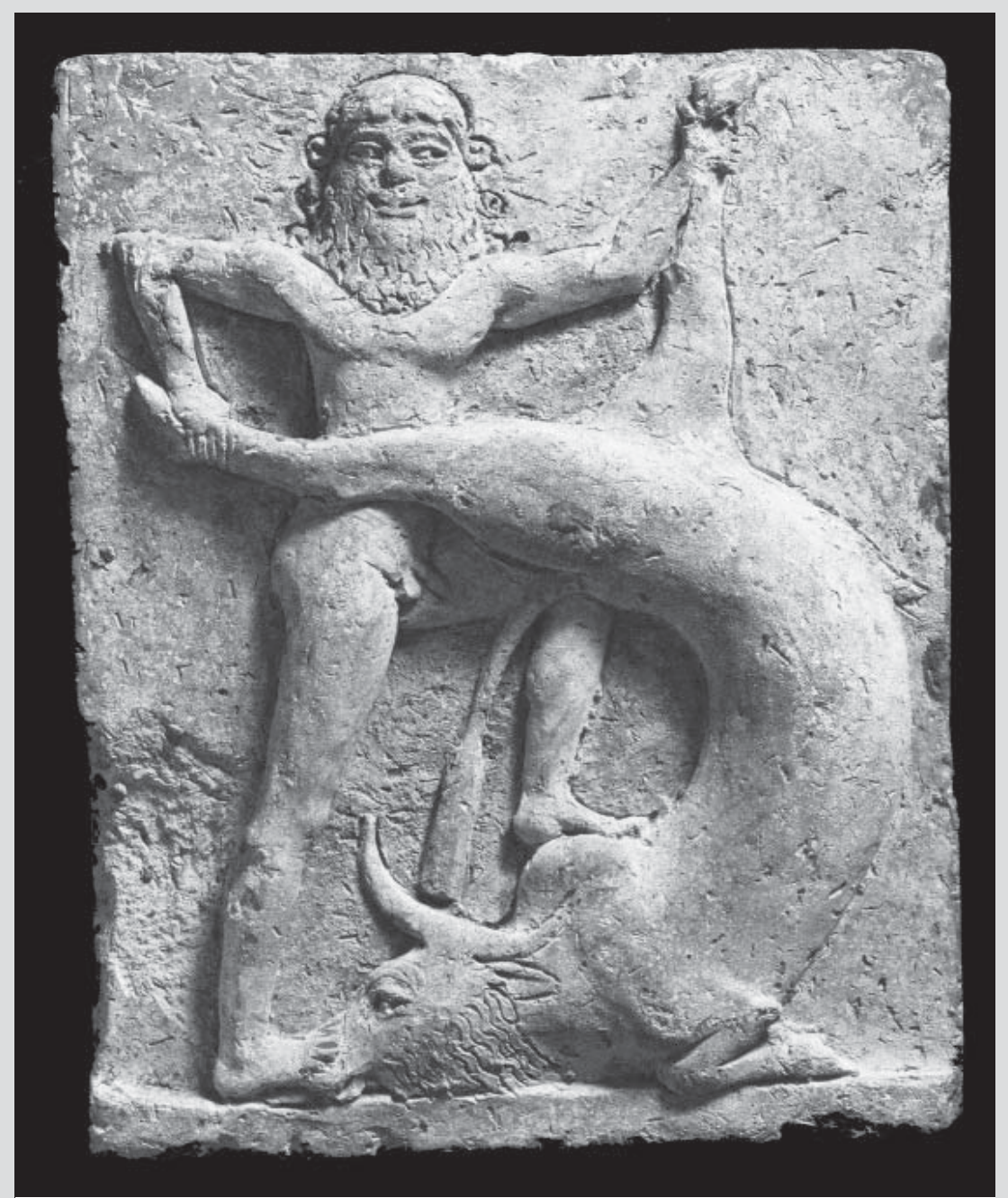

02. RELIEVE VOTIVO. PERÍODO DEL REINO DE NARAM-SIN (2225-2219) O MÁS RECIENTE. TERRACOTA, RASTROS DE POLICROMÍA, MUSÉE ROYALE D'ART ET D'HISTORIE, BRUSELAS, 0.1024. LA POSTURA

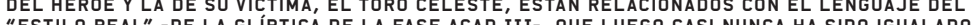
LA OPINIÓN MÁS COMÚN VE EN ELLA UN EPISODIO DE LÁ EPOPEYA DE GILGAMEŚ.

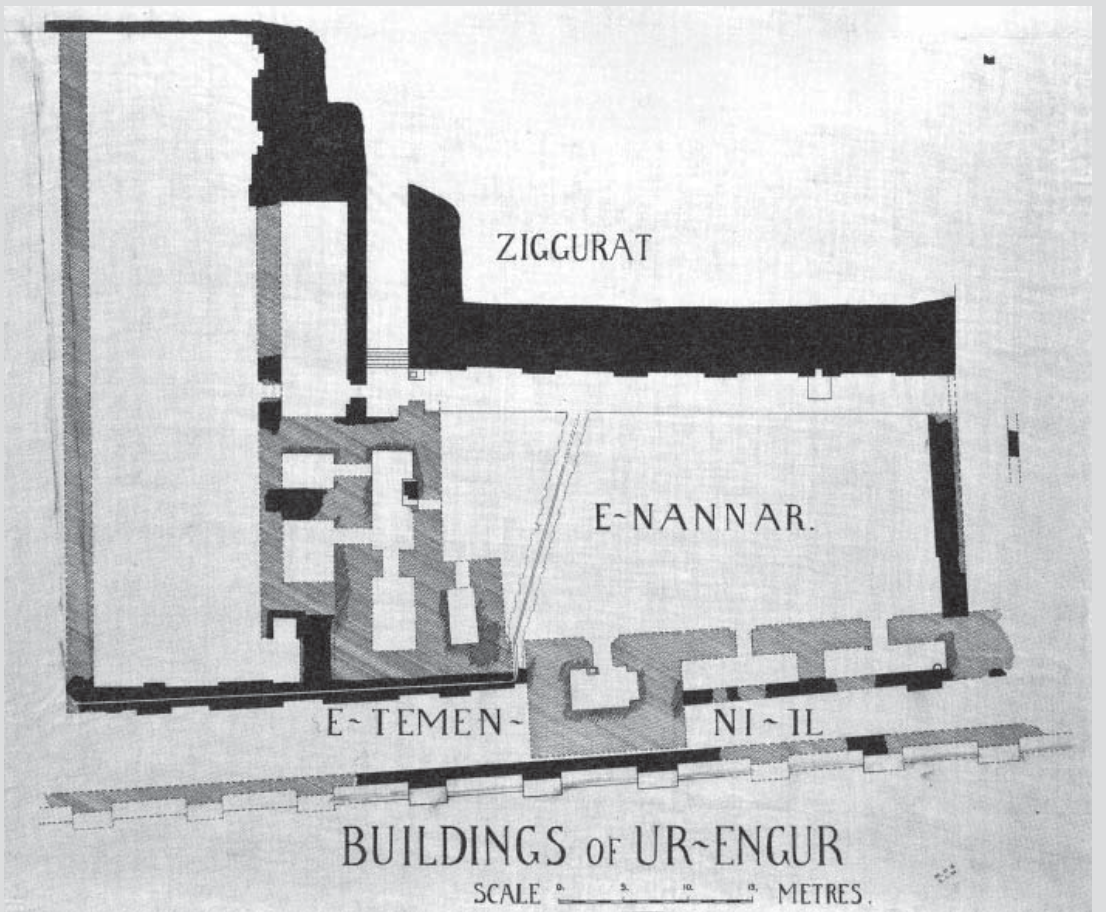

03. CHARLES LEONARD WOOLLEY. PLANTA DE LA ARTICULACIÓN DE LOS TRES EDIFICIOS SAGRADOS EN UR, A FINALES DEL III MILENIO, POR EL REY UR-ENGUR (O UR-NAMMU): EL ZIGGURAT, Y LOS TEMPLOS E-NANNAR Y E-TEMEN-NI-IL, DEDICADOS TODOS AL DIOS NANNAR (O NANNA), EL DIOS CHARLES LEONARD WOOLLEY, AŃOS 20030 . PLUMA Y TINTA SOBRE LINO. 100,3X73,6CM. PENN MUSEUM, FILADELFIA, EP-2012-2-9 (198706). 
J. Sanmartín, Epopeya de Gilgamesh, op. cit., p. 9I y s., 287 y s.

8.

A este respecto es importante la exposición "Uruk 5000 Jahre Megacity", Vorderasiatisches Museum, Staatliche Museen zu Berlin (25/04 - o8/og/ 20I3; http:// www.uruk-megacity.de/).

9.

J.C. Fincle, "Shaggashu (Murderer), the Demon from the Steppe”, en: Bibliotheca Orientalis 70, 2013, p. I8-23.

IO.

F. Nietzsche, Vom Nutzen und Nachteil der Historie für das Leben, Werke in drei Bänden, herausgegeben von K. Schlechta, vol. I, München I969.

II.

E. Sollberger / J.-R. Kupper, Inscriptions royales sumériennes et akkadiennes, Paris I97I; D.O. Edzard, "Königsinschriften. A. Sumerisch", en: Reallexikon der Assyriologie und Vorderasiatischen Archäologie, Band 6, Berlin / New York I983, p. 59-65; J. Renger, "Königsinschriften. B. Akkadisch", en: Reallexikon der Assyriologie uns Voderasiatischen Archäologie, Band 6, Berlin / New York I983, p. 65-77.

I2.

\section{Para la política}

constructora de los soberanos asirios Asiria y su reflejo en la documentación literaria regia véase S. Lackenbacher, Le Roi bâtisseur. Les récits de construction assyriens des origines à Teglatphalasar III, Paris I982.

I3.

E. Sollberger / J.-R. Kupper, Inscriptions royales sumériennes et akkadiennes, op. cit., p. 40.

I4.

Escrito Gu-NI.DU;

lectura real insegura.
Ser ${ }^{8}$.

La Nada, o peor que la Nada: Los viajeros y mercaderes de la Antigüedad, en Siria y Mesopotamia, sentían un auténtico terror al atravesar las estepas que separaban los oasis fluviales, sedes de las ciudades. El largo brazo de la ley terminaba en las fronteras de las áreas urbanas, y allí comenzaban las zonas en las que mandaba el desorden y el crimen. Si la ciudad era la sede del dios y de su rey, y por tanto de la kittu ("seguridad") y el misharu ("derecho"), es decir del Ser, la estepa estaba poblada por habbatu ("bandidos") y shaggashu ("asesinos") 9 . Por si ello no bastaba, el campo estaba plagado de etemmu ("espíritus") pertenecientes a víctimas asesinadas y no enterradas debidamente, y un sinfín de demonios de vario pelaje que merodeaban amenazando a la gente y que contagiaban enfermedades y propagaban toda serie de males sólo con el tacto.

\section{LA MEGALÓPOLIS (DE LA MANO DE LA HISTORIA)}

"En cuanto jueces, tendríais que estar más en alto que los que van a ser juzgados; mientras que vosotros sólo habéis llegado más tarde. Los huéspedes que llegan los últimos a la mesa merecen que se les dé los últimos sitios: ¿̇y queréis tener los primeros? Pues haced al menos lo más alto y más grande; quizás entonces se os haga sitio de verdad, aunque hayáis llegado en el último momento" Io

Entre los documentos cuneiformes que nos ha legado la antigua Mesopotamia, uno de los géneros mejor representados es el de las inscripciones reales: Documentos redactados por voluntad del rey y explícitamente destinados a perpetuar su memoria ${ }^{\mathrm{II}}$. En sus formas más generales están presentes tanto en la tradición en lengua sumeria como en la acadia y abarcan desde la época protodinástica, en pleno III milenio a. d. C., hasta la época persa, en la segunda mitad del I. Estas inscripciones reales pueden dividirse en varios subgéneros.

Uno de ellos, quizás el más relevante, lo constituyen las denominadas inscripciones conmemorativas, que se refieren a la construcción, dedicación, conservación o reparación de edificios: Templos para las diversas divinidades principalmente, pero también obra civil. Los "autores" suelen ser reyes o altos funcionarios investidos de autoridad regia por delegación. Los textos provienen básicamente del núcleo mesopotámico de tradición sumerio-acadia: Babilonia y sus barrios culturales inmediatos Kish, Ur, Lagash, Umma, Uruk, Adab, Shuruppak, Eshnuna, Isin, Larsa, Ur, etc.; además, de los ámbitos más al norte y oeste de este núcleo: Asiria, con su capital Assur en la cuenca media del Tigris ${ }^{12}$, y la Siria eufrática con su centro en la ciudad de Mari. Y arrancan en las épocas más remotas de la tradición escrita madura: el así llamado período presargónico, a mediados del III milenio a. d. G. (en torno al 2600).

Están grabadas o escritas sobre los soportes más diversos, siendo los más frecuentes la arcilla (tablillas, prismas, cilindros, conos y ladrillos), piedra (estelas y lápidas), paredes de roca u objetos preciosos. Así, p. e., la inscripción votiva redactada en lengua sumeria y grabada sobre lapislázuli en la ciudad de Kish hacia el 2460 a. d. C.:

Para el dios An, rey de todo el país, y la diosa Inanna, reina de las diosas. Lugaltarsi, rey de Kish, ha construido la muralla del atrio ${ }^{\mathrm{I} 3}$.

O la placa votiva de Ur-Nanshe, rey de Lagash, del siglo XXV a. d. C.:

Ur-Nanshe, rey de Lagash, hijo de GuNIDU ${ }^{14}$, el hijo de Gursar, ha edificado el templo del dios Nin-Girsu, ha edificado el Abzubanda, ha edificado el templo del dios Nanshe ${ }^{\text {I5 }}$. 


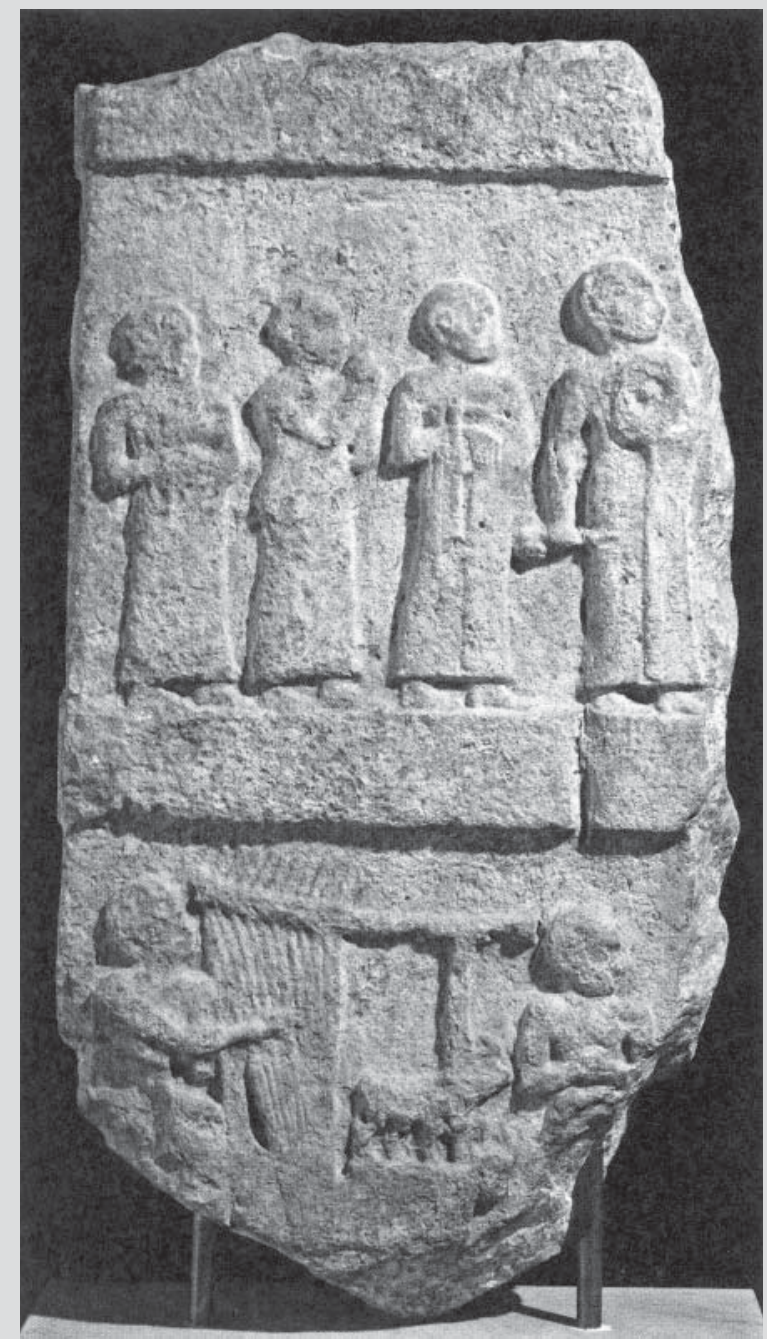

04. ESTELA FRAGMENTARIA QUE REPRESENTA A GUDEA ANTES DE LA CONSTRUCCIÓN DEL TEMPLO. LA LIRA QUE OCUPA EL REGISTRO
INFERIOR ACOMPANABAA A LOS RITOS. TELLO, EXCAVACIONES E. DE SARZEC, 1880. PIEDRA CALIZA. ALTURA CONSERVADA: $125 \mathrm{CM}$. MUSÉE DU LOUVRE, PARÍS, A052.

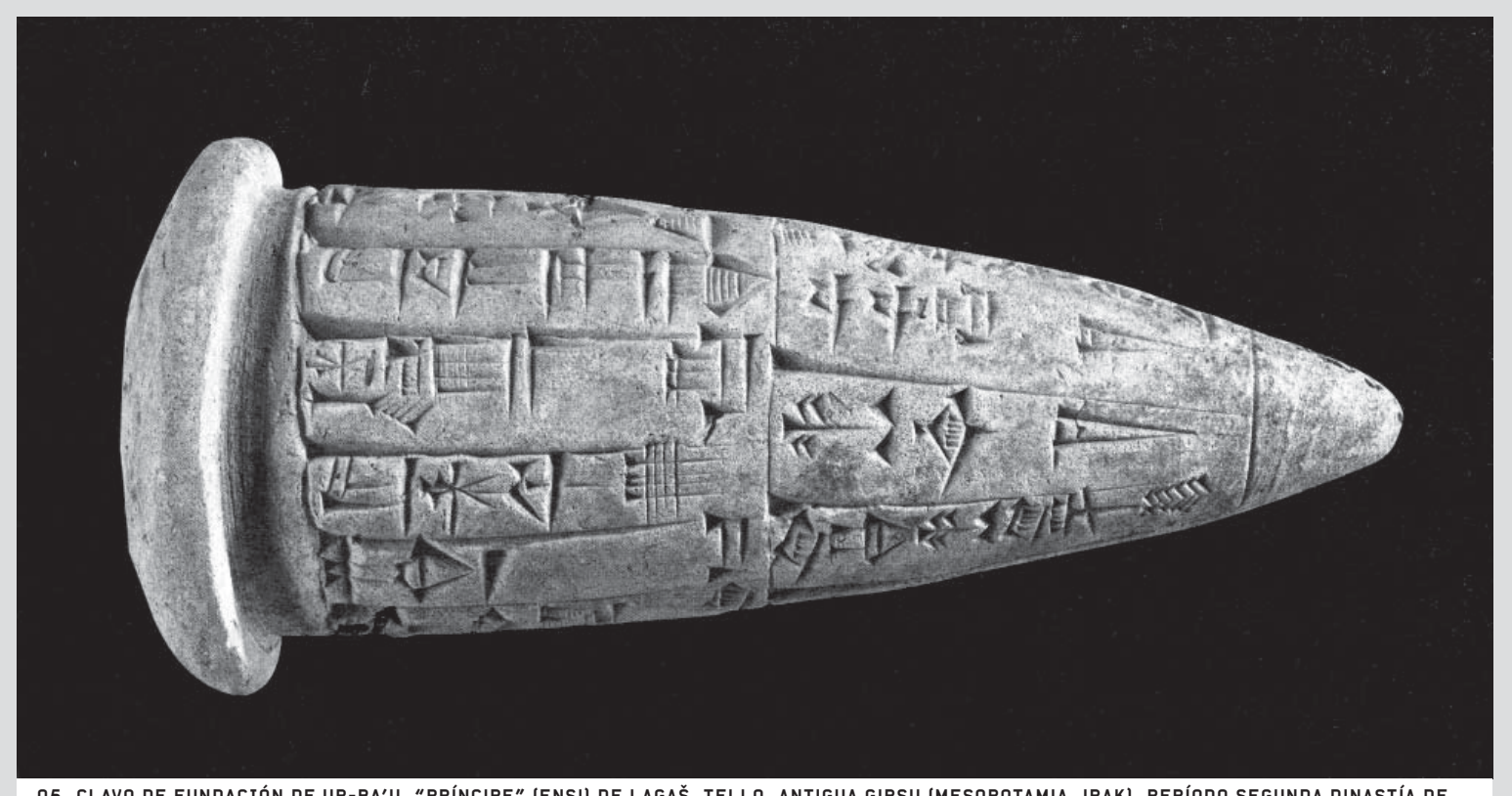

05. CLAVO DE FUNDACIÓN DE UR-BA'U, “PRÍNCIPE” (ENSI) DE LAGAŠ. TELLO, ANTIGUA GIRSU (MESOPOTAMIA, IRAK). PERÍODO SEGUNDA DINASTÍA DE LAGAS, CA.
A021036. 
E.A. Braun-Holzinger, Mesopotamische Weihgaben der frühdynastischen bis altbabylonischen Zeit, Heidelberg I99I, p. 308

I6.

E.A. Braun-Holzinger, Mesopotamische Weihgaben, op. cit. p. 3I5.

I7.

E. Heinrich, Paläste im Alten Mesopotamien (Deutsches Archäologisches Institut: Denkmäler antiker Architektur 15), Berlin I984.

I8.

J. Bretschneider, "The ,Reception Palace' of Uruk and its Architectural Origin”, en: J. Bretschneider /J. Driessen / K. van Lerberghe (eds.), Power and Architecture. Monumental Public Architecture in the Bronze Age Near East and Aegean, Leuven / Paris / Dudley, Ma 2007, p. II-22.

I9.

La traducción "Buen Pastor" responde al original sumerio SIPA-ZI "pastor seguro" o "fiel" (atestiguada desde Eannatum I, ca. 2400 a. d. C.), en la titulación acadia rếû kInu (desde los reyes Kurigalzu II, ca. I400 a. d. C., y Salmanassar I, I274I245); cf. M.-J. Seux, Épithètes Royales Akkadiennes et Sumériennes, Paris I967, p. 244-250, 44I-446.

20

M.-J. Seux, Épithètes Royales, op. cit., p.75 (reyes Shulgi, ca. 2050 a. d. C., y Samsu-Iluna, ca. I730 a. d. C.).

$2 \mathrm{I}$

M.-J. Seux, Épithètes Royales, op. cit., p. 438 (rey WaradSin, ca. I830 a. d. C.)

22

M.-J. Seux, Épithètes Royales, op. cit, p. 356 (rey TukultiNinurta I, I244-I208 a. d. C.)
O del rey Gudea de Lagash, de época neosumeria (siglo XXI a. d. G.):

\section{[...] Para su Señora, Gudea, el príncipe de Lagash, ha edificado su templo de Uruk ${ }^{16}$.}

En este tipo de inscripciones conmemorativas se detecta una de las dimensiones esenciales de la función regia según la comprensión mesopotámica.

Conviene señalar que el estado fue siempre, en Mesopotamia, una estructura fuertemente centralizada, enraizada en los núcleos urbanos; éstos, a su vez, cristalizaron en torno a los templos. Todavía en nuestros días, las ruinas de los grandes templos mesopotámicos y las de sus torres escalonadas constituyen el dato más llamativo del paisaje arquitectónico iraquí y sirio.

La larga historia sirio-mesopotámica -más de tres mil años-y la enorme extensión geográfica del escenario - desde el Irán hasta el Mediterráneo- fueron ocasión y causa de diversos cambios de las concepciones urbanísticas y de las relaciones de poder que las determinaban. El régimen político de la ciudad-templo protodinástica (III milenio a. d. C.) había ido evolucionando hacia regímenes de monarquía absoluta basada en una ideología patriarcal (II milenio a. d. G.).

La monarquía autárquica se convirtió de este modo en la forma de gobierno definitiva para el resto de la historia, no sólo mesopotámica, sino de toda la Siria y el Asia Anterior. Frente a la variedad de la práctica política real que implicaban esta historia y este escenario inmensos, la ideología sobre la que se basaba tal ejercicio de la realeza se mantuvo relativamente estable, aunque en diversos sitios y épocas se pudiera acentuar un aspecto u otro. Conviene recordar que tanto el "templo" del dios como el "palacio" del rey tienen como idea matriz la "casa" ( $\mathrm{E}_{0}$ ) normal, en estos casos ampliada semánticamente en el lexema compuesto E -GAL "Casa Grande". Se trata de un esquema arquitectónico plenamente desarrollado por ejemplo en pleno III milenio Uruk y Eridu ${ }^{17}$, pero cuyos primeros diseños se detectan ya en la acrópolis de Tepe Gawra (Obeid 4, estrato XIII) en el v milenio ${ }^{18}$.

El programa del poder político se definía sucintamente por las funciones siguientes: El monarca era el pater familias y el "(buen) pastor" (SIPA en la titulación sumeria; $r e \bar{e} \hat{u}$ en la acadia) ${ }^{19}$. Ambas se combinan en los diversos theologoumena "guardián", "pastor de los cabezas negras" (vulgo: la humanidad), "guardián de las poblaciones que habitan tranquilas"20, "pastor que guarda el templo Ekishnugal"21, "mayoral que los mantiene en buen estado"22, etc.

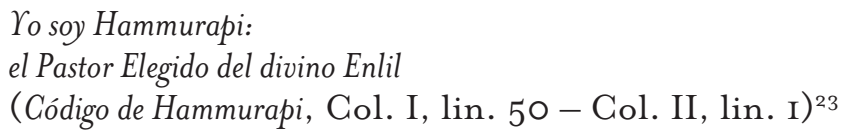

Yo soy Hammurapi:

el Pastor Elegido del divino Enlil

(Código de Hammurapi, Col. I, lin. 50 - Col. II, lin. I) ${ }^{23}$

Las primeras líneas del Código de Hammurapi, de la primera mitad del s. XvIII a. d. C., consisten en un vasto prólogo que enumera las cualidades y virtudes del monarca. Una vez establecida su regia personalidad por elección divina, Hammurapi presenta sus credenciales, entre la cuales, aparte su dedicación al mantenimiento de la justicia y de la estabilidad social, están la de "constructor" (sumerio DIM , DU $_{3}$; acadio bānû) y de "restaurador" (sumerio KI-Be ${ }_{2} \mathrm{GI}_{4}$, GIBIL, $\mathrm{MU}_{2}$; acadio mūddishu) de los templos y las ciudades de su reino:

Yo, (soy Hammurapi), el Acumulador de la abundancia y de la opulencia, el que ha llevado a buen término todo lo de la ciudad Nippur-Duranki (y es) devoto cuidador del templo Ekur ${ }^{24}$;

el Rey Eficiente que ha restaurado la ciudad de Eridu en su lugar (y) ha purificado el ritual del templo E'abzu, 
Yo soy la Semilla Regia producida por el divino Sin, el Enriquecedor de la ciudad de Ur,

el Devoto, el Fervoroso, el que aportó la abundancia al templo Ekishnugal;

J. Sanmartín, Códigos legales de tradición babilónica, Madrid / Barcelona I999, p. 85 y s., 98 .

Yo soy el Rey Prudente, obediente al divino Shamash,

el Poderoso que ha consolidado los cimientos de la ciudad de Sippar, el que ha revestido de frondosidad la capilla superior ${ }^{25}$ de la diosa Aya, el que ha hecho del templo Ebabbar un templo excelso, semejante a la morada de los cielos.

Yo soy el Guerrero Compasivo con la ciudad de Larsa, el renovador del templo Ebabbar para el divino Shamash, su aliado.

Yo soy el Señor Revitalizador de la ciudad de Uruk, el suministrador de aguas de la abundancia a su pueblo, el que ha levantado la cúspide del templo E’ana, el que ha acumulado abundancia para el dios Anu y la divina Ishtar.

Yo soy el Protector del País, el que ha reunido a las gentes dispersas de la ciudad de Isin, el que ha colmado de abundancia el templo de Egalmah.

Yo soy el Dragón de los Reyes, el hermano predilecto del divino Zababa, el consolidador de los cimientos de la ciudad de Kish, el que ha rodeado con un aura resplandeciente el templo Emete'ursag, el celebrante fiel de los solemnes oficios de la diosa Ishtar, el administrador del templo Hursagkalamma.

Yo soy la Red Cazadora de enemigos, a quien el dios Erra, su compañero, le concedió la consecución de sus deseos;

el Engrandecedor de la ciudad de Kuta, el que ha acrecentado inmensamente todo lo del templo Meslam.

Yo soy el Búfalo Feroz que cornea a los enemigos, el predilecto del dios Tutu, la alegría de la ciudad de Borsippa, el devoto que no abandona sus deberes para con el templo Ezida.

Yo soy el Dios de los Reyes, el Sabio perspicaz,

el Ampliador de los cultivos de la ciudad de Dilbad, el que apiló los silos para el divino Urash, el Audaz.

Yo soy el Señor Merecedor del cetro y la corona, a quien hizo perfecto la sabia diosa Mama;

el Diseñador de los planos de la ciudad de Kesh; el suministrador de los alimentos puros de la divina Nintu.

Yo soy el Prudente, el Perfecto,

el que adjudicó los pastos y los abrevaderos a las ciudades de Lagashy Girsu, el Suministrador de magnas ofrendas al templo Eninnu.

Yo soy el Cazador de Enemigos, el predilecto de la diosa Telitum que cumple los oráculos de Sugal, que alegra el corazón de la diosa Ishtar;

\section{$(\ldots \ldots \ldots)$}

Yo soy el Rey Vivificador de la ciudad de Adab, el Organizador del templo Emah. 
27.

El "País de Súmer y Akad" es una designación del núcleo cultural e histórico mesopotámico desde una perspectiva autóctona babilónica.

28.

J. Sanmartín, Códigos legales, op. cit., p. IOI y s.

29.

J. Sanmartín, Epopeya de Gilgamesh, op. cit., p. 287 y s.

30.

Catálogo: P. Azara (ed.), Antes del Diluvio. Mesopotamia 3500-2100 a.C., Barcelona 2012.

3I.

J.-L. Huot, "Los orígenes de la ciudad sumeria", en: P. Azara, Antes del Diluvio, op. cit., p. 7I-76; N. Yoffee,

"La arquitectura sumeria: Monumental y doméstica", op. cit., p. 77-80; B. André-Salvini, "Gudea de Lagash, 'El Arquitecto' del dios Ningirsu", op. cit., p. 8I-87; P. Michalowski, "En los comienzos: La civilización urbana de Súmer”, op. cit., p. 88-92.

32.

M. Liverani, "Stadt (city)", en: P. Streck (ed.), Reallexikon der Assyriologie und Vorderasiatischen Archäologie, Band 13, Berlin / Boston 2OII, p. 50-74.
Yo soy el Príncipe de los Reyes, irresistible en la guerra; el Donador de vida a la ciudad de Mashkan-Shápir, el que hartó de agua al templo Emeslam.

Yo soy el Sabio, el Buen Ecónomo; el que alcanzó las profundidades de la sabiduría;

el que acogió a los habitantes de la ciudad de Malgûm en la catástrofe, el cimentador de sus casas; el que, en la abundancia, decretó para el divino Ea y la divina Damgalnunna - los magnificadores de su reinoofrendas sempiternamente puras."

(Código de Hammurapi, Col. I, lin. 50 - Col. IV, lin. 22) 26 $^{26}$

Tras la enumeración de sus actividades como arquitecto, reparador de ciudades y templos, de cuidador de las imágenes divinas y sostenedor del culto, Hammurapi resume su aura en una serie de autotítulos que nos dan la clave histórico teológica de su política:

Yo soy el Primero entre los Reyes $(\ldots \ldots \ldots)$

Yo soy el Príncipe Piadoso $(\ldots . . . .$.

Yo soy el Pastor de la Gente $(\ldots . . . .$.

Yo soy el Proclamador de lo jurídicamente inmutable $(\ldots \ldots \ldots)$

Yo soy el Silenciador de Rebeldes (........)

Yo soy el Piadoso Orante ante los Grandes Dioses;

el descendiente de Sumula'el, poderoso heredero de Sinmuballit, semilla eterna de la realeza;

yo soy el Rey poderoso,

el Sol de Babilonia que hace amanecer la luz sobre el País de Súmer y Akkad ${ }^{27}$,

el Rey Sometedor de los Cuatro Cuadrantes, el Protegido de la divina Ishtar.

(Código de Hammurapi, IV $23-\mathrm{V} 24)^{28}$

Desde esta perspectiva, se entiende que Gilgamesh, al volver a Uruk y, en los últimos versos de su Epopeya, reencontrarse consigo mismo y con su misión regia, le mostrase a su barquero Ur-Shanabi lo esencial de su obra como rey-arquitecto, las murallas en las que se encerraba la megalópolis:

Le dijo Gilgamesh a él, a Ur-Shanabi, el barquero:

"iSube, Ur-Shanabi, a la muralla de Uruk;

paséate por ella;

examina los fundamentos,

fijate en el enladrillado!

¡A ver si esa obra

no es de ladrillo cocido

y si sus cimientos no los echaron

los Siete Sabios!”

(Gilgamesh, Tablilla XI, lin. 32I-328) ${ }^{29}$

Los textos, las fotos y demás materiales que acompañan e ilustran la magnífica exposición "Antes del Diluvio" (CaixaForum Barcelona / Madrid, noviembre 2012 - junio 2013 $)^{30}$ contienen abundante información sobre la arquitectura sumeria y la función del rey como constructor ${ }^{3 \mathrm{I}}$. M. Liverani ha publicado recientemente un estudio excelente sobre el urbanismo mesopotámico ${ }^{32}$.

Sabemos que, a finales del III milenio a. d. C., Uruk era la mayor ciudad del mundo, la world city. Se calcula que tendría entre 30.000 y 40.000 habitantes, y estaba protegida por una muralla en la que se encerraban 250 ha. En el interior del recinto convivía un vecindario heterogéneo ${ }^{33}$. Básicamente se componía de artesanos 
(madera, metal, cueros, lanas, cestería, albañilería; todos ellos ramificados en infinitas subespecialidades); escribas y sus escuelas, comerciantes y distribuidores de productos alimentarios (centralizados en "tabernas", "panaderías" o una combinación flexible de ambas); mercaderes y agentes comerciales o de cambio y bolsa con sus dependientes empleados; propietarios de tierras e inmuebles en la ciudad, su extrarradio y otras localidades, y por último, innumerables funcionarios de las grandes instituciones centrales: los templos y la corte real. Muchos de los habitantes de la urbe estaban relacionados laboralmente -más o menos a tiempo parcial o completo- con estos dos enormes hubs ideológicos y económicos.

La muralla urbana mesopotámica no tiene un nombre específico: $\mathrm{BAD}_{3}$, en sumerio, y dūrum, en acadio significan simplemente "muro" o "pared". La ciudad amurallada puede contener una serie de muros interiores que separan entre sí los barrios y, sobre todo, uno o varios que protegen su núcleo más precioso: los complejos palaciales y los templos. Así, por ejemplo, estamos especialmente bien informados sobre el muro y puertas de la ciudad santa denominada $E_{2}$-NINNU ANZU.MUSEN-BABBAR (Eninnu- "Águila-Blanca") construida por Gudea ${ }^{34}$. Los arqueólogos han conseguido hacerse una idea medianamente clara de la planimetría de la muralla mesopotámica a lo largo de sus más de 3000 años de historia, sujeta como estuvo a evidentes variaciones por razón de los materiales disponibles, el tamaño de la ciudad, las oscilaciones de la política y la economía palaciegas y las circunstancias medioambientales y topográficas. Aparte el muro mismo, sus elementos básicos fueron bastiones y torres distribuidos regularmente y distantes entre ellos no más de unos de $35 \mathrm{~m}$ (alcance medio efectivo de jabalinas, flechas, hondas, etc.). Cuando la topografía lo requería se construyeron en paralelo al muro fosos - secos o llenos de agua- y glacis de tierra apisonada, piedras y cascotes, frecuentemente pavimentados.

Los cálculos de altura y por tanto de volúmenes son más complejos y a menudo imposibles debido a la ausencia de restos de superestructuras; una rara excepción es la ciudad de Assur, una de las capitales del Imperio Asirio y núcleo ideológico suyo ${ }^{35}$.

Todo ello se refiere a lo que podríamos describir como "ciudad interior", o "corazón de la ciudad" (libbi ălim en acadio) ${ }^{36}$. La muralla, ovoidal, estaba dotada de varias puertas; cada una de ellas constituía el centro social del respectivo barrio, el cual se encontraba frecuentemente separado de los demás por muros interiores: a la sombra de la puerta se reunía el consejo comunal, se solucionaban los litigios y se intercambiaban noticias. A tener muy en cuenta: Todo indica que la ideología arquitectónica de las puertas en las muralla urbanas mesopotámicas -su teleologíaera más la de impedir la entrada que la de permitir la salida.

La puerta (en sumerio: $\mathrm{KA}_{2}$ y ABUL; en acadio: bābum y abullum) hacía de puente entre dos mundos: el de la in-sistencia urbana cerrada y ordenada y el de la ex-sistencia abierta. Las puertas estaban flanqueadas por torreones, coronadas por superestructuras almenadas (conservadas en muy contadas ocasiones), protegidas a veces por rampas y puestas bajo la vigilancia de una guardia especial (EN.NU.UN.ABUL.LA en sumerio, massar abullim en acadio) ${ }^{37}$. Todo un síntoma, y toda una analogía con las aberturas fisiológicas, ya que la puerta no sólo sirve para salir, sino también para entrar, de modo que la puerta ventila y, a la vez, pone en peligro el sistema inmunológico. La situación y planificación de la puerta de la ciudad mesopotámica tiene lugar -en consonancia con la idiosincrasia teleológica de la muralla- de acuerdo con criterios predominantemente estratégicos, sin concesiones especiales a la política civil de comunicaciones ni, de suyo, a la topografía $a^{38}$. La anchura no sobrepasaba los dos metros en las puertas del iii milenio a.C.; eran construcciones defensivas y no necesariamente monumentales; aunque la literatura compara con gigantes héroes desnudos- las torres que flanqueaban la puerta de la ciudad de Akkad ${ }^{39}$. Normalmente se emplearon ladrillos para su construcción, solos o sobre cimientos de piedra; el dintel podía ser recto o arqueado. El paso mismo de la puerta solía estar cubierto, y nunca era directo o sencillo, sino que se prolongaba en una serie

Los registros arqueológicos más completos son probablemente los que tienen por objeto la ciudad de Ur. Cf. P.R.S. Moorey, Ur' of the Chaldees', Ithaca I982; K. Keith, "The Spacial Patterns of Everyday Life in Old Babylonian Neighborhoods", en: M. Smith (ed.), The Social Construction of Ancient Cities, Washington 2003, p. 56-80. Los datos pueden extrapolarse a otras ciudades: R. McC. Adams, Heartland of Cities. Surveys of Ancient Settlement and Land Use on the Central Floodplain of the Euphrates, Chicago I98I; H. Nissen, Grundzüge einer Geschichte der Frühzeit des Vorderen Orients, Darmstadt I983, p. 4I-I39.

34 .

Cf. W. Heimpel, "The Gates of the Eninnu", Journal of Cuneiform Studies 48, 1996, p. I7-29. Sobre Gudea arquitecto, B. André-Salvini, "Gudea de Lagash, 'El Arquitecto' del dios Ningirsu", en: P. Azara, Antes del Diluvio, op. cit. p. $8 \mathrm{I}-87$.

35.

W. Andrae, Das widererstandene Assur. 2., durchgesehene und erweiterte Auflage herausgegeben von Barthel Hrouda, München 1977 [= I9I3], figs. I89 y I9O.

36.

Entre los títulos regios:

"Constructor de la muralla de la Ciudad Interior" (rey Salmanassar III, 782-773 a. d. C.); M.-J. Seux, Épithètes Royales, op. cit., p. I9.

37.

E. Cancik-Kirschbaum, "Stadttor. A. Philologisch. In Mesopotamien", en: P. Streck (ed.), Reallexikon der Assyriologie und Vorderasiatischen Archäologie, Band 13, Berlin / Boston 20II, p. 86 y ss.

D.P. Mielke, "Stadttor. C. Archäologisch", en P. Streck (ed.), Reallexikon der Assyriologie und Vorderasiatischen Archäologie, Band 13, Berlin / Boston 20II, p. 9I-97. 
39.

F.A.M. Wiggermann, Mesopotamian Protective Spirits The Ritual Texts, Groningen I962, p. I64-I66.

40.

J. Sanmartín, Códigos legales, op. cit., p. I5.

$4 \mathrm{I}$

P. Sloterdijk, Sphären II. Globen, Frankfurt am Main I999, p. 275 y s.

42

M. Liverani, "Ancient Near Eastern Gities and Modern Ideologies", en: G. Wilhelm (ed.), Die orientalische Stadt. Kontinuität, Wandel, Bruch, Berlin I997, p. 85-IO7. de espacios más o menos discontinuos, de anchura variable; normalmente, un espacio anterior o corredor y un callejón de una o varias cámaras según el modelo de las llamadas "puertas en pinza", frecuentemente -en los modelos más antiguos-en ángulo recto respecto al trazado de la muralla propiamente dicha. Todo ello no al servicio de la sociedad "civil" y de su desarrollo, sino a fin de prolongar la finalidad defensiva de la puerta.

El conflicto ideológico que planea entre los aspectos comunitarios e inmunitarios de la puerta la dota de una semiótica bipolar. La prueba de esta ambivalencia peligrosa la proporcionan las figuras apotropeicas y estatuas sobredimensionadas de genios encargadas de protegerla, y los rituales y ofrendas que se celebran en su ámbito. Antes de nada, sin embargo, la puerta es la primera y última manifestación del poder regio ante la nada extra-urbana. En ella se administra justicia, y ella marca el límite de lo permitido y lo prohibido:

[\$ I5] Si un hombre deja que un esclavo del palacio, o una esclava del palacio, o un esclavo de un (individuo) cualquiera, o una esclava de un (individuo) cualquiera, salgan por la puerta principal de la ciudad, será ejecutado.

\section{(Código de Hammurapi, Col. VIII, lin. 30-36) ${ }^{40}$}

Más allá de la puerta comenzaba un ámbito satélite tanto más difícil de controlar ideológica, teológica y políticamente cuanto más alejado del corazón: La "ciudad exterior" (URU-BAR-RA en sumerio), el sector de los servicios constituido por una corona de barracas, almacenes, huertas, eras, corrales, pozas para la extracción de arcillas, etc., y una especie de zona franca, dotada de cierta autonomía fiscal y administrativa que llamaban "el muelle" (KAR en sumerio, kārum en acadio), domicilio de los mercaderes propios o extranjeros, bolsa de intercambio, estación o meta de las caravanas o de los convoyes fluviales, etc.

Pero ese más allá de la puerta quedaba ya lejos del eje / pivote cósmico que, a través del corazón de la ciudad -su templo- unía el mundo superior AN, morada del dios celeste Anu, y con el submundo inferior, o KI. En las afueras de la ciudad comenzaba la nada, sacudida por vientos, genios y gentes malignos. La ciudad era la civitas dei. De este modelo bebió el de la "Nueva Jerusalén" y lo de extra Ecclesiam nulla salus.

Desde este momento, la política, la arquitectura y la teología se contraen en un proyecto macroinmunológico común.

\section{(P. Sloterdijk) $)^{4}$}

Llegados a este punto creemos necesario formular un caveat: No existe "la" ciudad mesopotámica -como no existe ni existió la "ciudad oriental"- sino en las mentes de la recepción ideológica y arqueológica a lo largo de la historia, desde Heródoto, Platón y Ktesias hasta nuestros postmodernos. La realidad se nos aparece cada vez más como un mosaico multicolor compuesto de piezas claramente diferenciadas en su morfología y en su ideología ciudadana subyacente. Así, y por lo que atañe a Mesopotamia de la primera mitad del ii milenio a. d. C. (la llamada época PaleoBabilónica), Mario Liverani ha descrito el panorama acertadamente: Assur, capital del Imperio Asirio a orillas de Tigris medio, fue una ciudad caravanera centrada en la producción y exportación de tejidos; Mari, en la cuenca media del Éufrates, era un enorme palacio construido entre tribus de pastores en gran medida (semi) nómadas; Sippar, un asentamiento disperso aglutinado en torno al templo del dios solar Shamash; Ur, un puerto dedicado al tráfico marítimo, a la sombra de un pasado imperial; Eshnunna, una pequeña fortaleza agresiva; Larsa, una ciudad agrícola; Babilonia, una capital imperial con altos y bajos; Nippur, un centro semisagrado dominado por núcleos de teólogos y escribas guardianes de la tradición religiosa y literaria pero carente de autonomía política ${ }^{42}$. 


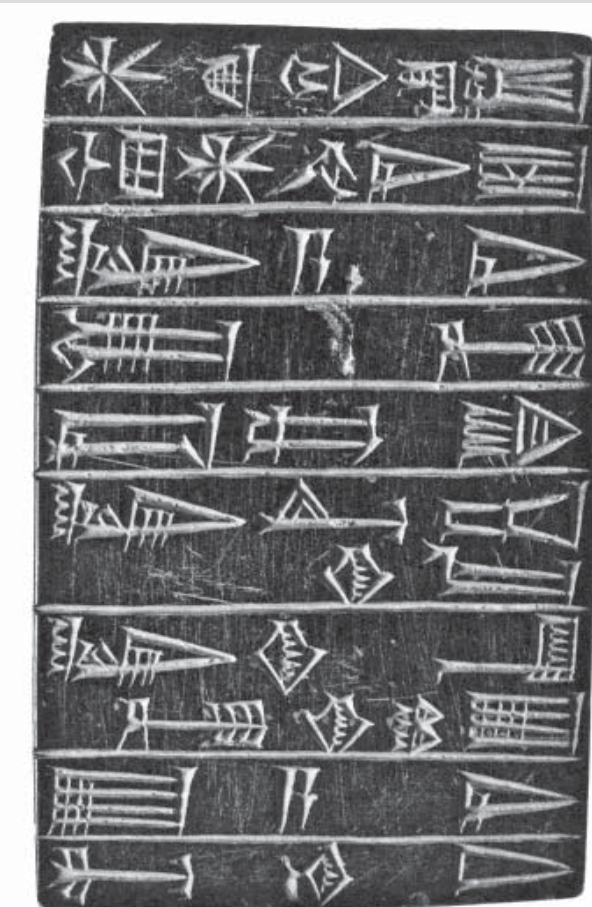

06. TABLA FUNDACIONAL DE ŠULGI, REY DE UR, CON UNA INSCRIPCION DEDICADA A SULLAT Y HANIS (EEANIA). ADUNTÍA DE UR DURANTE EL REINADO DE ŠUERERA 2050 A. . J PIEDRA NEGRA, IIX6,7 CM. ORIENTAL INSTITUTE MUSEUM, CHICAGO, A3700.

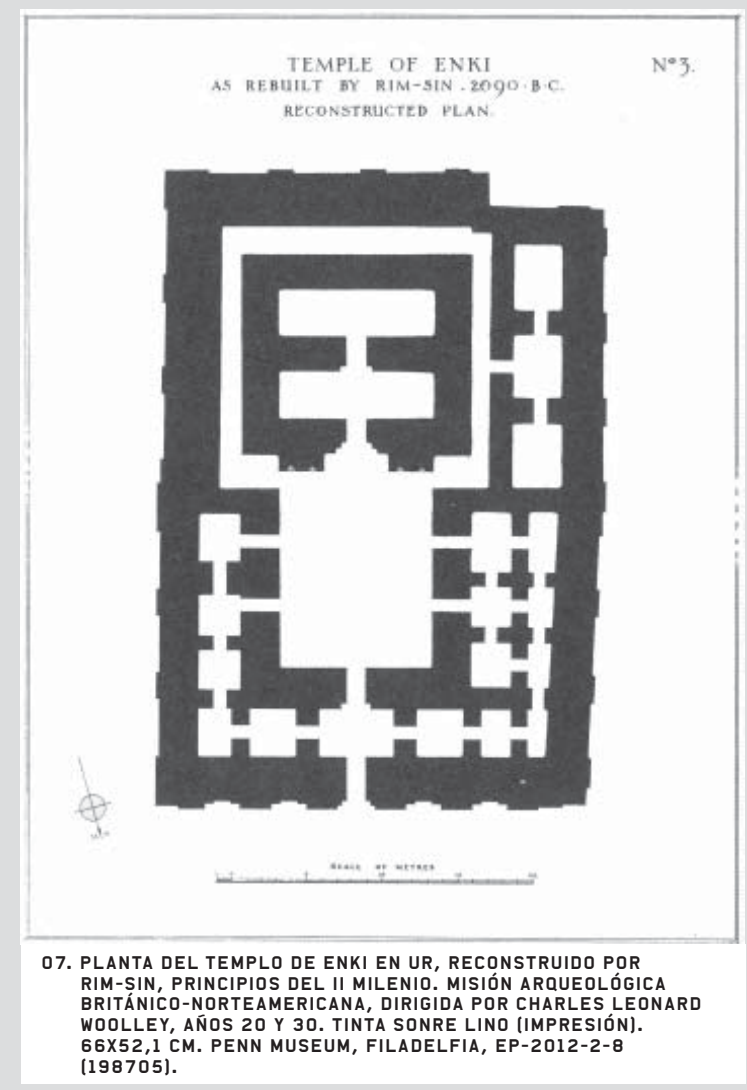

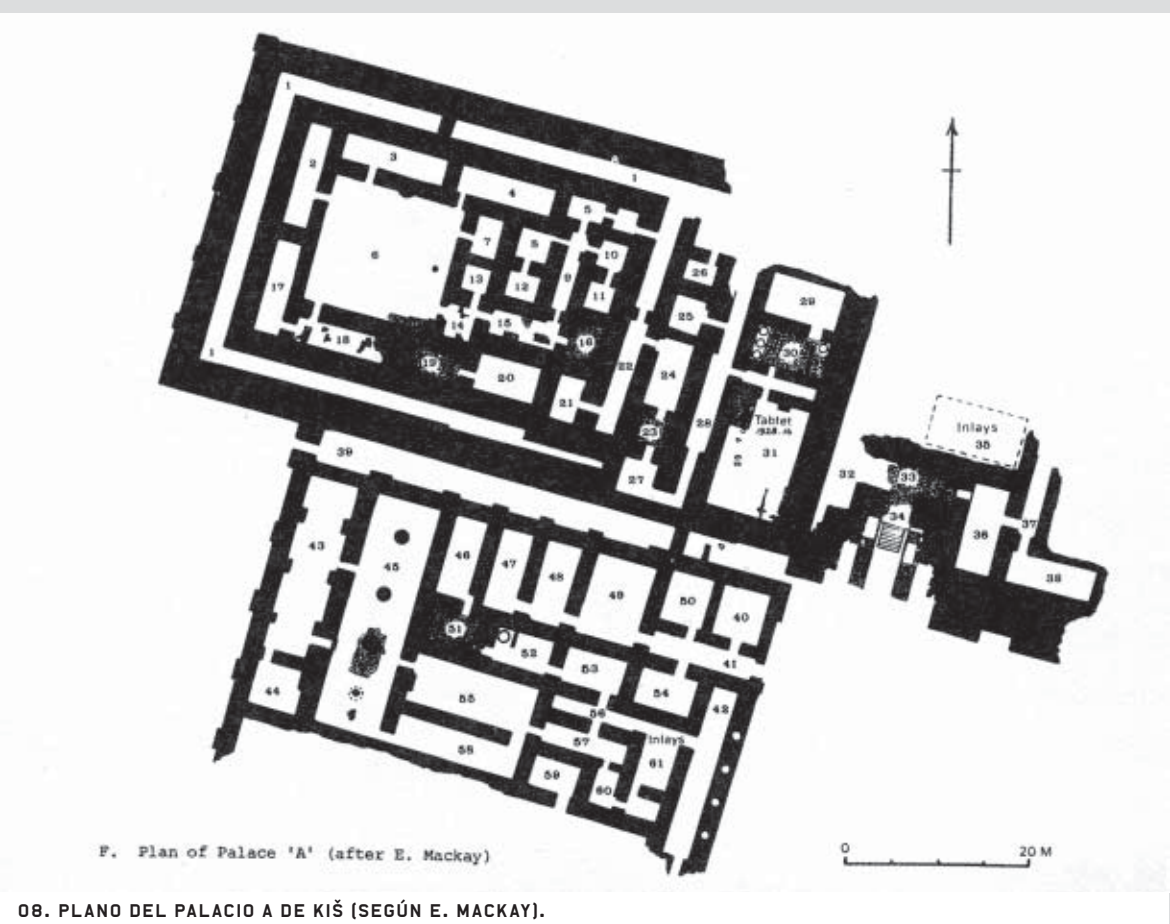




\section{HEREMENEUSIS (DE LA MANO DE SLOTERDIJK)}

43.

F. Nietzsche, Vom Nutzen und Nachteil der Historie für das Leben, Werke in drei Bänden, herausgegeben von K. Schlechta, vol. I, München I969.

44 .

P. Sloterdijk, Sphären II: Globen, op. cit., p. 268.

45 .

Städtebauendes Tier en expresión de O. Spengler, Der Untergang des Abendlandes. Umrisse einer Morphologie der Weltgeschichte, II, München I990 [= I923], p. 66I. A renglón seguido: "La Historia universal es la historia del urbanícola (die Geschichte des Stadtmenschen)".

46.

P. Sloterdijk, Sphären II: Globen, op. cit., p. 270 y s.
"Cada uno de nosotros tiene que organizar el caos en su interior volviendo a concentrarse en sus necesidades auténticas. La sinceridad, el carácter firme y verdadero tienen que rebelarse en algún momento contra ese continuo repetir, empollar, imitar. Comienza a comprender que la cultura puede ser otra cosa que decoración de la vida, es decir, en el fondo, solamente disimulo y tapujo; porque todo adorno esconde lo adornado" 43

Gilgamesh era rey: Había construido las murallas y templos de su ciudad (una de las ciudades de mejor pedigrí desde los tiempos más remotos), guerreado contra sus regios colegas, explorado los bosques más frondosos y escalado los montes más altos, matado a los ogros más feroces, flirteado con las diosas, degollado toros celestes y conocido los recovecos más sombríos del Submundo infernal. Sus hazañas se cantaban en sumerio y acadio -las lenguas escolásticas básicas-, y además en hitita y hurrita. Pero su barquero era un extranjero primitivo, acostumbrado a plomizos horizontes marinos y playas sin gente, que se encontraba por vez primera con un monstruo, una ballena habitable:

¿[...] Qué otra cosa sería una ciudad del tipo de las metrópolis mesopotámicas regio-divinas (Gott-Königs-Metropolen), vista con los ojos del hombre primitivo, que una explanación de la tesis según la cual, en la culturas superiores (Hochkulturen), lo descomunal se presenta como obra humana? ¿Y qué otra cosa son esas construcciones de formas extrañas, vistas desde afuera, que máquinas de salvamento con las que los hombres se han esforzado en compensar su específica ostensión de angustia del mundo (ihre spezifische Offenbarung von Weltangst) y han levantado monumentos monstruosos a su voluntad de no quedarse afuera (ihrem Willen zum Nicht-aussen-Sein)?

\section{(P. Sloterdijk) 44}

La ciudad contenía todo lo humano -porque el hombre es un animal que edifica ciudades ${ }^{45}$-elevado a la categoría de (único) Ser:

Las primeras ciudades están ahí para capturar las miradas, atraerlas hacia las alturas, humillarlas. Su desenfrenada visibilidad declara la guerra al ojo ingenuo y le exige sumisión a esa escena centelleante, desafiadora y persistente. El fenomenólogo de lo protohumano (Urmensch-Phänomenologe) que quisiera volver a alzar su mirada a los muros de Jericó o de Babilonia tendría primero que tener claro que esta ciudad, con su indisimulada presencia, ha puesto en desuso la manera de ver que tenía hasta este momento. Sólo quien haya visto una ciudad como ésta podrá decir de sí mismo que sabe en qué consiste una aparición. En la ciudad -y sólo en la ciudad-puede comprobarse lo que significa una formación (ein Gebilde) que apuesta sin reservas por lo contrario de ocultarse (das Gegenteil von Verborgensein) y se planta en el centro de la visibilidad.

\section{(P. Sloterdijk $)^{46}$}

La ciudad es el continente de lo humano y también -y sobre todo- de lo divino. La ciudad mesopotámica y la ciudad actual encarnan ambas el ser inamovible. Y en ella, en la ciudad, en su grandeza y altura, se manifiesta y revela el dios patrono: Anu, el Celeste, en Uruk; Marduk en Babilonia, Assur en Nínive, el Khristós Pantókratōr en Bizancio, la Santísima Trinidad en el baldaquín vaticano, el índice Dow Jones en Wall Street:

La ciudad se alza ahí como una construida pretensión de verdad, de validez, de duración; quiere encarnar un ser que permanece inconmovible en su tranquila 


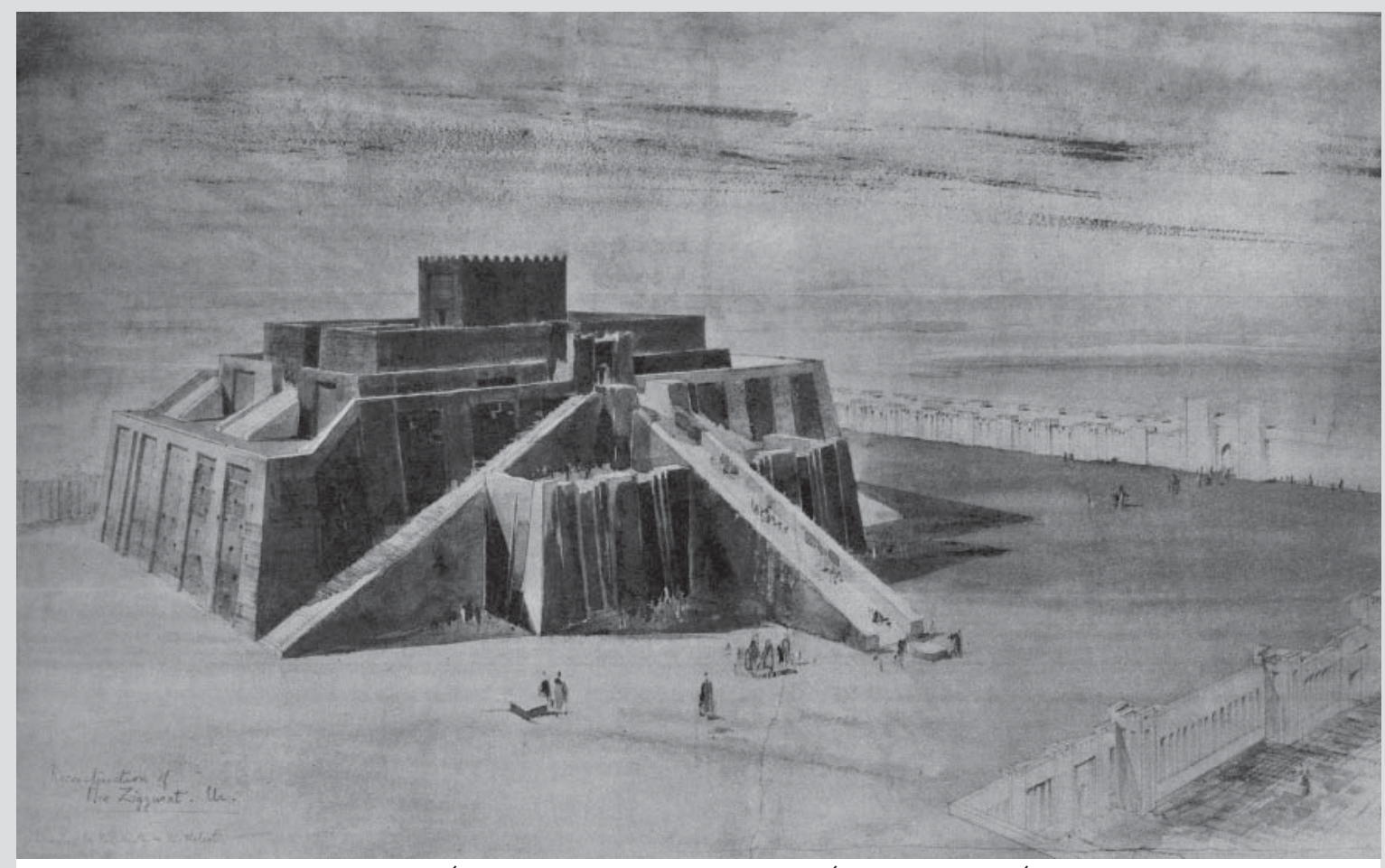

09. F. G. NEWTON Y W, WALCOT, RECONSTRUCCIÓN DEL ZIGURAT DE UR TAL Y COMO APARECÍA TRAS SU EDIFICACIÓN A FINALES DEL III MILENIO. MISIÓN ARQUEOLÓGICA BRITÁNICO-AMERICANA, DIRIGIDA POR SIR CHARLES LEONARD WOOLLEY, AÑOS 20 Y 30, 75 X35 CM, THE BRITISH MUSEUM, LONDRES.

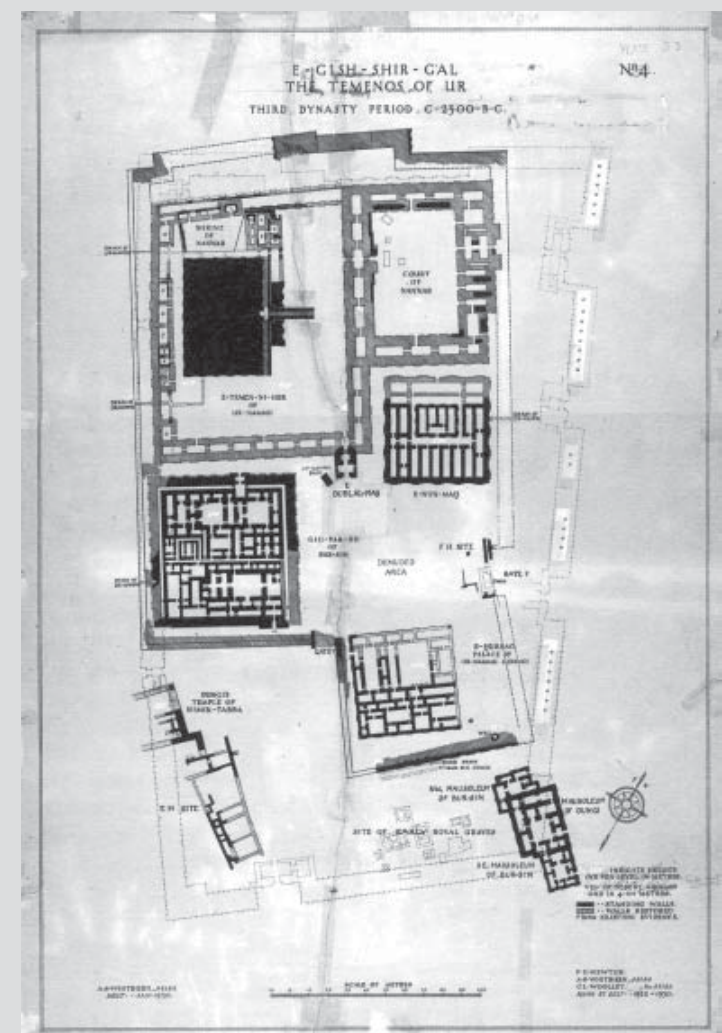

10. F. G. NEWTON. PLANTA DEL E-GIŠ-ŠIR-GAL O RECINTO SAGRADO DE UR, EN TIEMPOS DE UR III (FINALES DEL III MILENIO), 1922-1930, PLUNA Y TINTA SOBRE LINO, 11,8X76, CM, PENN MUSEUM, FILADELFIA, EP-2012-2-10 (225427).

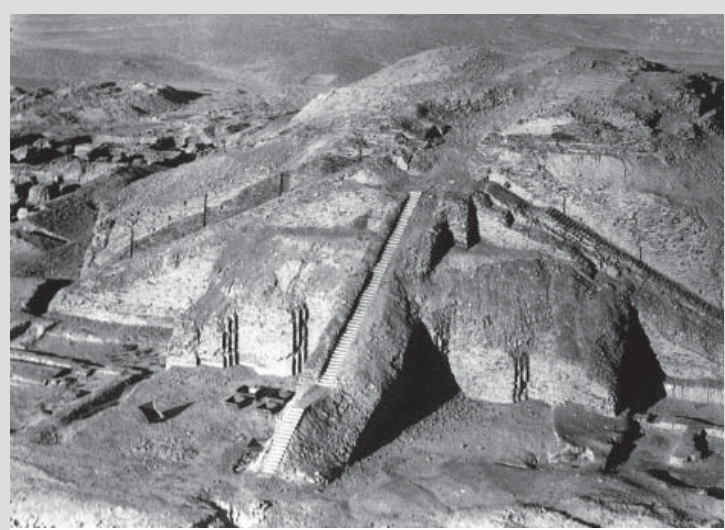

11. FOTOGRAFÍA DEL ZIGURAT DE UR TOMADA POR LA ROYAL AIR FORCE EN IRAQ A LA ORDEN DE LEONARD WOOLLEY, 1930. 1617 - PENN MUSEUM, FILADELFIA. HTTP://WWW.
PENN.MUSEUM/BLOG/MUSEUM/UR-DIGITIZATION-PROJECTNOVEMBER-2012/ATTACHMENT/191617/ 
47.

P. Sloterdijk, Sphären II: Globen, op. cit., p. 272.

48.

Véase T. Kämmerer / K.A. Metzler, Das babylonische Weltschöpfungsepos 'Enūma elîsh', Münster 20I2. Las citas remiten siempre a esta edición.

49.

T. Kämmerer / K.A. Metzler, Das babylonische Weltschöpfungsepos, op. cit.

50.

Nombre del templo de Marduk en Babilonia.

$5 \mathrm{I}$.

Pirámide escalonada monumental en cuya plataforma superior solía construirse un santuario.

52.

Nombre mitológico de la región situada entre el plano inferior del Cielo y el Océano Inferior.

53.

P. Sloterdijk, Sphären II: Globen, op. cit., p. 279. magnificencia, visible también para una segunda o tercera mirada; quiere estar vigente incluso para una última mirada [...] La ciudad no relampaguea como un meteoro al que el ojo pretenda en vano retener. Claro que en la manera en que una ciudad se presenta de pronto ante nosotros hay cierto flamear, una augusta subitaneidad, pero este relámpago desde abajo se convierte en una imagen estática, presencia durable y, por mucho que el ojo se fije en esa masa orgullosa, no habrá ni centelleos ni concesiones a lo efímero en la imagen que se nos aparece. Nada en la existencia grandiosa y penetrada de sí misma de las murallas permite deducir una tendencia a desvanecerse. Lo que se aparece aquí, y permanece en su aparición, es la negativa misma de la transitoriedad. El aparecerse está henchido de la energía de quedarse, y en tal voluntad de quedarse (Bleibe-Wille), la humanidad temprana, iluminada fenomenológicamente, tiene por vez primera la experiencia de un nuevo tipo de dioses.

(P. Sloterdijk) ${ }^{47}$

Las ciudades y los templos son, para los habitantes de la antigua Mesopotamia, el centro del mundo; edificarlos es la primera misión de los reyes y de sus modelos celestes, los dioses. A finales del II milenio a. d. C. se compuso en Babilonia la 'Epopeya de la Greación del Mundo', el Enūma elîsh ("Cuando en lo alto...") ${ }^{48}$ para mayor gloria del dios de la capital y del mundo, Marduk. El texto de la Epopeya ofrece una hermenéutica del nombre 'Babilonia', denominada 'Casas-de-los-GrandesDioses", pues es allí donde ellos se reúnen y celebran sus fiestas (Tablilla V, lin. I29-I30). Babilonia es la obra personal de su dios, Marduk, que afirma:

Voy a edificar una casa que sea residencia de mi plenitud.

En su interior fundaré sus templos,

estableceré mi santuario y aseguraré mi dignidad regia.

(Enūma elîsh, Tabilla V, lin. I22-I24) ${ }^{49}$

El "santuario" (kummu) del dios y su "realeza" (sharrūtu) van de la mano, como han ido de la mano significantes y significados desde que en el mundo hay signos. El mismo dios Marduk -arquitecto atento "que ha diseñado el plano (ișratu)" de su capital residencial- da sus instrucciones a los obreros, los dioses, sobre el modo de llevarā a cabo la empresa e invita a sus divinos colegas a la inauguración:

\section{"Levantad Babilonia, la obra que habíais codiciado: \\ Háganse ladrillos, y ponedle nombre al templo." \\ Los dioses manejaron la azada, \\ durante un año fabricaron los ladrillos.}

Al llegar el segundo año

alzaron las cabezas desde el Esagil ${ }^{50}$, copia del Océano Inferior.

Crearon la alta ziqqurāt ${ }^{51}$ del divino Océano,

y establecieron las moradas de los divinos Anu, Ellil, Ea y del mismo Marduk. Con gesto majestuoso se les colocó delante,

sus dos cuernos se fijaron en los cimientos del Esharra ${ }^{52}$.

$(\ldots \ldots \ldots)$

"Esta es la Babilonia lugar de vuestra morada.

Exultad en la sede de Marduk; sentaos para solaz suyo."

Se sentaron los Grandes Dioses;

se pusieron delante las jarras de cerveza, tomaron asiento para el banquete.

(Enūma elìsh, Tablilla VI, lin. 57-72) ${ }^{53}$ 
Los dioses, en nuestro caso las divinidades mesopotámicas, son los prototipos de una soberanía arquitectónica -que no otra cosa es la ciudad - en la que se visualiza el poder en la forma de imperio amurallado y sistema macro-inmunológico coherente. Desde los tiempos de Uruk, el prototipo de la ciudad, y desde Gilgamesh, el prototipo del rey, se funden la política, la arquitectura y la teología en un solo sistema cuya clave está en lo que Schopenhauer llamaba "la voluntad de vivir" (der Wille zum Leben) y luego Nietzsche, más adecuadamente, "la voluntad de poder" (der Wille zur Macht), y con todo ello el poder de transformar el mundo. Las ziqqurāt, las torres escalonadas babilónicas, las altas murallas de Uruk no se construyeron para observar el cielo ni la tierra. Son vehículos de una revelación, de una epifanía del poder ante sí mismo.

La primera clave del fenómeno de la ciudad nos la proporciona la reflexión sobre la relación de nuevo tipo que se establece entre el poder de la ciudad y la estructura religiosa urbana. Lo que, en las primeras ciudades mesopotámicas, parece presentarse como el preludio en la historia universal de un continuo de la voluntad de poder (Kontinuum des Willens zur Macht), se funda en la revolucionaria experiencia de la capacidad de fijar, mediante construcciones propias de márgenes (durch eigene Rand-Konstruktionen), una forma de mundo en la que el espacio interior se ha ampliado literalmente con fuerza y por la fuerza.

(P. Sloterdijk) $)^{54}$

Típicamente Gilgamesh: el rey-arquitecto creyó que su deber, ante sí mismo y por su pueblo, consistía en levantar muros y templos lo más altos posible para manifestarse como autorealización de lo divino.

No son ensueños faltos de medios los que mueven a los constructores de Uruk, Nínive o Babilonia a dar las órdenes de levantar torreones y fortalezas. En ellos reside ya la experiencia práctica de ser capaces de poder transformar radicalmente el mundo visible. Gozan ya de esta borrachera arquitectónica que utiliza la técnica del ladrillo para edificar de nuevo el mundo imperial interior, la caverna reinante.

(P. Sloterdijk) $)^{55}$

Muchos alcaldes han seguido las huellas de Gilgamesh.

La ciudad mesopotámica es, por lo demás, una realidad paradójica: Busca la seguridad en medio de la espectacularidad. La clave de esta contradicción aparente se encuentra en las murallas, su formato y su volumen.

Nos encontramos ante ese monumentalismo autoritario que les había parecido tan repugnante a los judíos que lo contemplaron, y tan digno de imitación a los competidores mesopotámicos - ese trazo sobredimensionado sin el que la historia de las potencias mundiales de la construcción (en tanto que se presentan como potencias del hardware) no puede concebirse. En sus comienzos, el monumentalismo es resultado de un ademán teotécnico (theotechnische Gebärde): Los constructores estaban convencidos de la obligación, ante sí mismos y ante su dios, de apilar con sus propias manos lo excelso tan alto como posible - o, lo que es lo mismo, de dejarse emplear para la autorrealización de lo divino.

\section{(P. Sloterdijk) $)^{56}$}

El papel de la ciudad como emblema -y no sólo refugio- del poder no se entiende sin la dimensión teológica del urbanismo. Se trata de una teología con una clara dimensión teleológica: La cohabitación de lo humano y lo divino en la ciudad marca
55.

Ibídem.

54.

P. Sloterdijk, Sphären II: Globen, op. cit., p. 279.

56.

P. Sloterdijk, Sphären II: Globen, op. cit., p. 297 y s. 
57.

P. Sloterdijk, Sphären II: Globen, op. cit., p. 305 y s.

58.

P. Sloterdijk, Sphären II: Globen, op. cit., p. 305 y s.

59.

P. Sloterdijk, Sphären II: Globen, op. cit., p. 299.

60.

"Mauer-Staaten", P. Sloterdijk, Sphären II: Globen, op. cit., p. 3II.

6I.

"Gesellschaft der dünnen Wände”, P. Sloterdijk, Sphären II: Globen, op. cit., loc. cit.

62.

M.-J. Seux, Épithètes Royales, op. cit., p. 75 (rey Neriglissar, 559-556 a. d. C.)

63.

Cf. R. Dulau / P. Mory (eds.), Torres y rascacielos: De Babel a Dubái, Fundación "la Caixa", Barcelona 2012 (Catálogo de la exposición en CaixaForum Madrid, IO/IO/2OI2 05/OI/2013). las formas de pensar del hombre - representado por su rey- y el dios que habita entre ellos. La categoría transcendente es ahora el espacio arquitectónico:

Lo que aparece como megalomanía a los ojos del observador procedente de una condición real de pequeñez y que piensa en pequeño no es, en el fondo, sino la confrontación de los ciudadanos con la una real misión de grandeza. ¿Qué hacer cuando unas dimensiones realmente vastas, cuando la multiplicidad real y las complejidades provocadoras fuerzan a rediseñar los mapas geográficos interiores? ¿Cómo comportarse cuando, en el punto en que nos encontramos, se ha instalado una divinidad clarividente que sólo acepta como residencia un mundo completo? ¿Cómo corresponder a esta exigencia de mundo por parte del dios, gemelo interior (innerer Zwilling) del rey y de todos los que le sucedan, si no es edificando un espacio universal interno (Weltinnerraum) excelso y vasto por medios arquitectónicos? Conforme la inteligencia avanza como una vista desde lo alto, implanta vistas sobrehumanas en las ópticas humanas: Los hombres participan de la visión del mundo de sus dioses y comparten con ellos el peso y la euforia de las grandes panorámicas. El formato es el mensaje, la dimensión es el dios.

(P. Sloterdijk) $)^{57}$

La arquitectura urbana mesopotámica - el vasto oval amurallado que alberga el templo, su ziqqurāt escalonada, el palacio real, los domicilios de los funcionarios y artesanos, los almacenes de grano y lana, los corrales de ganado y las pozas arcillosas que producen millones de ladrillos. Esa arquitectura es el signo eficiente de la comunidad genética entre lo humano y lo divino, y el sacramento sólo puede ser administrado por la mitad humana de la pareja de gemelos: El rey.

Sólo porque el dios, gemelo resplandeciente del conmocionado individuo, se ha transformado en el gran dios, un dios urbano y regio preñado de mundo, tienen que seguir las mitades humanas de esta pareja de gemelos (Zwillingspaar) a su íntimo otro en sus aventuras impetuosas.

\section{(P. Sloterdijk) $)^{58}$}

La "teología del monumentalismo" 59 y la consiguiente fórmula social del "estado-muro" ${ }^{60}$ estaba destinada a dominar el urbanismo y la concepción general de la ciudad hasta mediados del pasado siglo xx. A partir de entonces, sin embargo, se detecta como novedad mundial el advenimiento de la "sociedad de las paredes finas" "ir (vulgo: "globalización"). Ello implica - como resultado o como causa- un nuevo concepto de la habitabilidad del espacio, y una revolución en el mundo de la arquitectura / de los arquitectos.

La misión del rey-arquitecto mesopotámico, el "(buen) pastor" -como se vio más arriba- era la de encerrarse con su grey en un gigantesco corral con-céntrico pensado para una visibilidad interior. Uno de los títulos regios es precisamente "el que cierra como una muralla sólida la entrada al país." 62

La vocación del arquitecto (post)moderno parece ser la de encerrar a cada single en una celda individual (vulgo: apartamento), y reunir esas celdas en colectores / hyperbuildings más o menos ex-céntricos en los que el exterior manda sobre lo interior, en los que la altura no se manifiesta en bases vagamente piramidales - como la en las ziqqurāt babilónicas- sino en estructuras transparentes que flotan sin conexiones evidentes con el suelo, ni con la lateralidad o la vecindad. La materia levita ${ }^{63}$. 
Uno, que no es del gremio y cuyos contactos con la arquitectura se reducen a observar con recelo o admiración lo que otros hacen, tiene la impresión de que la figura del rey-arquitecto se ha convertido en la de arquitecto-rey: una inversión de términos que sí afecta al producto. "Doing Their Own Thing (Philip Johnson)" fue la cabecera de TIME hace ya más de treinta y mucho pico de años (8 de enero de 1979).

Conscientes de su dimensión sagrada, algunos reyes-arquitecto sumerios y babilónicos estuvieron muy cerca de considerarse, ocasionalmente, "dioses". En especial, y a finales del iii milenio a. d. C., la dinastía III ("neosumeria") de Ur acentuó decididamente el vocabulario religioso relativo a la monarquía, aunque a nosotros nos sea muy difícil precisar el alcance teológico o metafísico de esa tendencia. Por ejemplo el rey Shulgi (en torno al $2094-2047$ a. d. C.), segundo monarca de esta dinastía, y a partir de una determinada fecha, antepuso sistemáticamente a su nombre el signo DINGIR "dios" y se autotituló "dios del país" (en sumerio: DINGIR KALAM-MA). Este signo representa en realidad una estrella. Con ligeras variantes, la estrella fue usada por sus sucesores en el trono de Ur III y luego, en la ciudad de Isin, por el rey Lipit-Ishtar en su intento de continuar la ideología de Ur. Con anterioridad, un título parecido, "dios [DINGIR: "estrella"] de Akkad", había sido aplicado ya en una ocasión por sus subordinados al rey Naram-Sin (en torno al 2254-2218 a. d. C.). Sin embargo, la divinización de los reyes de Ur III no se repitió en la historia mesopotámica, lo que invita a situar el uso del signo dingir "estrella" en un contexto más político que teológico: estas tendencias fueron cristalizando poco a poco en una conceptualización meramente "sobrehumana" de la persona y la función del rey. En realidad el rey está revestido de una divinidad funcional y estrictamente ligada a su oficio ${ }^{64}$. En la misma documentación de la época del rey Shulgi e inmediatamente siguiente nos encontramos con expresiones y frases que relativizan el alcance de la divinización: el monarca es "como" un dios, es el dios "de los hombres" y "el más famoso de los humanos":

Rey mío: Tu palabra es la palabra del divino An ('Cielo'), que no se cambia; cuando decides el destino, la decisión te la ponen en la mano como a un dios

\section{$(\ldots \ldots \ldots)$}

Tú eres el dios de los hombres desde Abajo hasta Arriba.

(De una carta de un ministro al rey Shulgi, Ur III, en torno al 2050 a. d. C.) ${ }^{65}$

Yo soy el dios de la humanidad; el más famoso de entre los numerosos seres humanos.

(De un himno sumerio en honor del rey Lipit-Ishtar, época paleobabilónica, en torno al ig30 a. d. G. $)^{66}$

O, para formularlo de otra manera: Los reyes se convirtieron en alter ego terrenal de sus dioses ${ }^{67}$.

Para enjuiciar estos procesos de esporádica divinización del rey en Mesopotamia hay que rechazar los modelos interpretativos extraídos de otras culturas, como la egipcia. Básicamente, la diferencia fundamental entre la tendencia humanizante que la cultura mesopotámica tiene del rey y la concepción divinizante que Egipto tiene de sus faraones radica en el carácter estrictamente político de esta divinización. El uso ocasional del signo DINGIR "estrella" por ciertos monarcas a finales del III milenio a. C. hay que entenderlo desde la función misma del rey como fuente de prosperidad
64.

G. Selz, "Götter der Gesellschaft - Gesellschaft der Götter. Zur Dialektik von Abbildung und Ordnung", en: H. Neumann / S. Paulus (eds.), Wissenskultur im Alten Orient. Weltanschauung, Wissenschaften, Techniken, Technologien, Wiesbaden 2012 , p. 6I-85.

65.

C. Wilke, "Zum Königtum in der Ur III-Zeit", en: P. Garelli (ed.), Le Palais et la royauté: Archéologie et civilisation. XIXe Rencontre Assyriologique Internationale [...] Paris 1971, Paris 1974 , p. I79.

66.

W.H.Ph. Römer, Sumerische 'Königshymnen' der Isin-Zeit, Leiden I965, p. 55 .

67.

P. Steinkeller, "On Rulers, Priests and Sacred Marriage: Tracing the Evolution of Early Sumerian Kingship", in: K. Watanabe (ed.), Priests and Officials in the Ancient Near East, Heidelberg I999, p. IO3-I37. 
68.

P. Sloterdijk,

"Architekten machen nichts anderes als InTheorie: Peter Sloterdijk im Gespräch mit Sabine Kraft unf Nikolaus Kuhnert", Der ästhetische Imperativ. Schriften zur Kunst, hrsg. von P. Weibel, Hamburg

69.

Ninguno de estos rasgos se detecta por ejemplo su "apartamento turístico" (2009) del Paseo de Gracia, en Barcelona. 70.

Idoù kainà poiô pánta (Apocalipsis de Juan, Cap. 2I verso 5 ).

7 I.

G. Binder, "I973-20I3, 40 años que impusieron el rascacielos a través del mundo", en: R. Dulau / P. Mory (eds.), Torresy rascacielos, op. cit., p. 2 II.

72.

Respecto a Mesopotamia, ello podría exigir por parte de los arqueólogos y sus arquitectos una metodología de análisis correctora y complementaria que preste atención a una visión from ground level, como ha sido propuesta recientemente para Khorsabad, capital del imperio neo-asirio entre 7I7 y 706 a. d. C. Cf. A. McMahon, "Space, Sound, and Light: Toward a Sensory Experience of Ancient Monumental Architecture", American Journal of Archaeology II7, 2OI3, p. I63-I79.

73.

B. Pedde, "Das ,Neue Babylon'", Alter Orient aktuell 2, 200I, p. 8-I2. y bienestar: él es el genio de su país. Además, estos procesos estaban avalados por la presencia en la literatura mesopotámica de héroes y reyes míticos semihumanos y semidivinos, como Gilgamesh, lo que hacía más fluctuantes las fronteras entre lo heroico, lo sobrehumano y lo propiamente divino.

Los (pocos) reyes-arquitecto mesopotámicos que - para acercarse a los dioses- recurrieron al signo DINGIR "estrella” coinciden en un vértice con los (muchos) arquitectos-rey del (post)modernismo: Su vocación estelar. El star system de unos y de otros, reyes-arquitecto o arquitectos-rey, tiende sus puentes a través de tres mil y pico de años de historia.

Común a reyes-arquitecto y arquitectos-rey "estelares" es el delirio de grandeza que desemboca en una vocación educadora, en virtud del

[... Aspecto megalómano latente en toda arquitectura. Y ello está absolutamente justificado porque como arquitecto se realizan propuestas de forma de vida bastante exigentes. Tan pronto como alguien levanta un edificio destinado a durar IOO años o más, está llevando a cabo una intervención enorme en las condiciones de vida [...] Resumiendo, los arquitectos harían muy bien en reconocer públicamente su megalomanía (Grössenwahn).

(P. Sloterdijk) ${ }^{68}$

Otra de las funciones compartidas por el rey-arquitecto mesopotámico y el arquitecto-rey postmoderno es la de difundir la felicidad entre las gentes. Toyo Ito, ganador (discutido y discutible) del último Premio Pritzker de Arquitectura (20I3), es descrito por el jurado como un creador de timeless buildings -y trazador de new paths-cuya arquitectura proyecta an air of optimism, lightness and joy ${ }^{69}$. Se añade otro rasgo común a mesopotámicos y (post)modernistas; la soteriológica en situaciones escatológicas: "He aquí que hago nuevas todas las cosas"7o. En el marco del "desarrollo sostenible", se apela al rascacielos como respuesta arquitectónica al problema de la escasez de suelo edificable en las megalópolis, sobre todo asiáticas pero no sólo asiáticas ${ }^{7 \mathrm{I}}$.

Los arquitectos saben que la megalomanía exige, por parte del usuario, una conciencia de su propia pequeñez. Los restos arqueológicos mesopotámicos han sido víctimas de una erosión (natural y antrópica) milenaria y carecen normalmente de volumen, de modo que el arqueólogo y el arquitecto tienen que conformarse a menudo con versiones meramente planimétricas, simplificadas, lo que empobrece radicalmente nuestra visión y desfigura el mensaje esencial de la monumentalidad, que no es otro que el control teológico (en Mesopotamia) y social (hoy) del espacio y de la población ${ }^{72}$. No conviene olvidar que se trata de edificaciones aplastantes por su altura, sus volúmenes (huecos o llenos) o por ambos, concebidas para ser vistas desde abajo por los de abajo, o desde lejos por los coleccionistas de skylines. Tanto los reyes-arquitecto como los arquitectos-rey (dos variantes del star system) no esperan de sus clientes / súbditos sino una respuesta: Wow! Quizás convenga recordar que los pioneros del skyscraper (Hugh Ferriss, Harvey Wiley Corbett) tomaron como modelos las torres escalonadas babilónicas (ziqqurāt) y recomendaron como lectura obligada para arquitectos la obra de G. Perrot y Ch. Chipiez "Histoire de l'Art de l'Antiquité, vol. II: Chaldée et Assyrie", de I884. Que no se trataba de meros modelos técnicos ni formales sino de genotextos muy serios lo ha mostrado Brigitte Pedde no hace mucho al comentar la mitología arquitectónica neoyorquina de los años treinta, y sus visiones de la Contemporary Babylon o New Babylon ${ }^{73}$. Por lo demás, las "siete torres" de la Moscú estalinista son el espejo socialista de los delirios capitalistas neoyorquinos. 


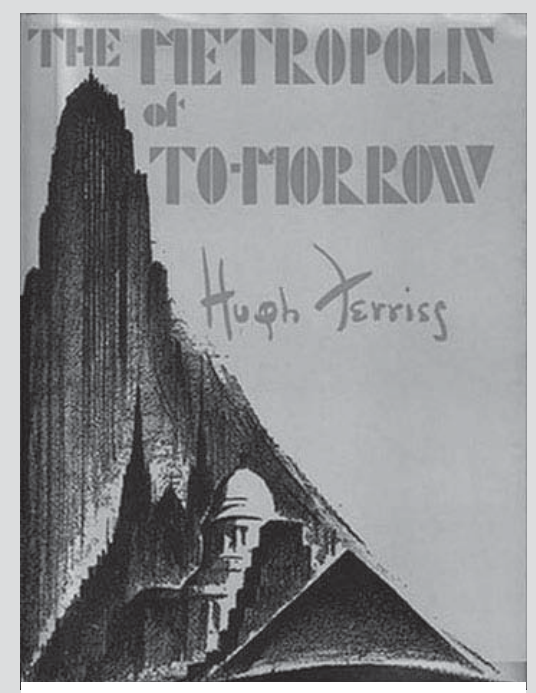

12. HUGH FERRISS, THE METROPOLIS OF TOMORROW, 1929

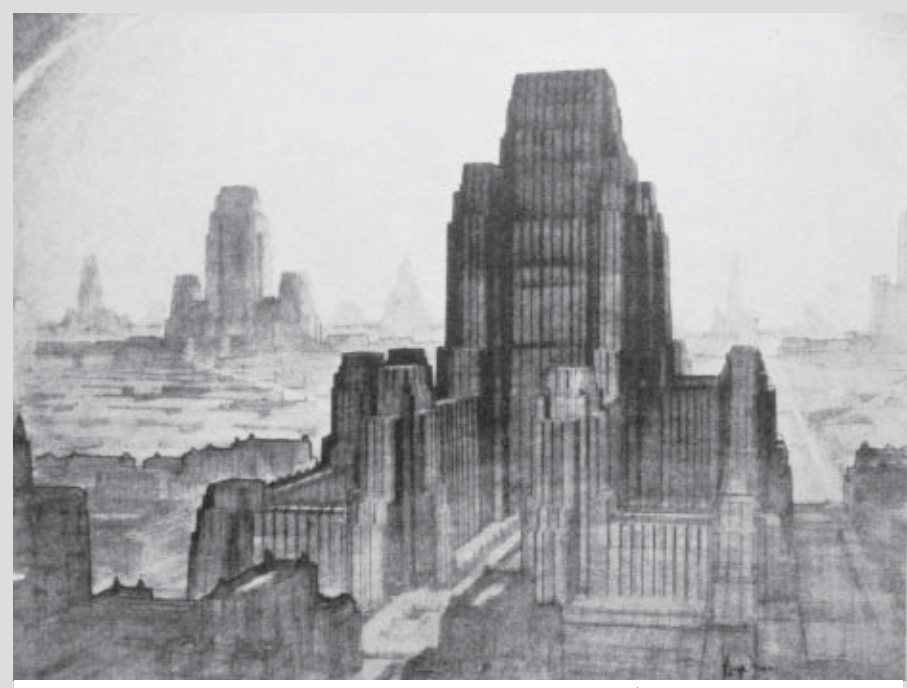

13. HUGH FERRISS, THE METROPOLIS OF TOMORROW, 1929, PÁGINAS INTERIORES.

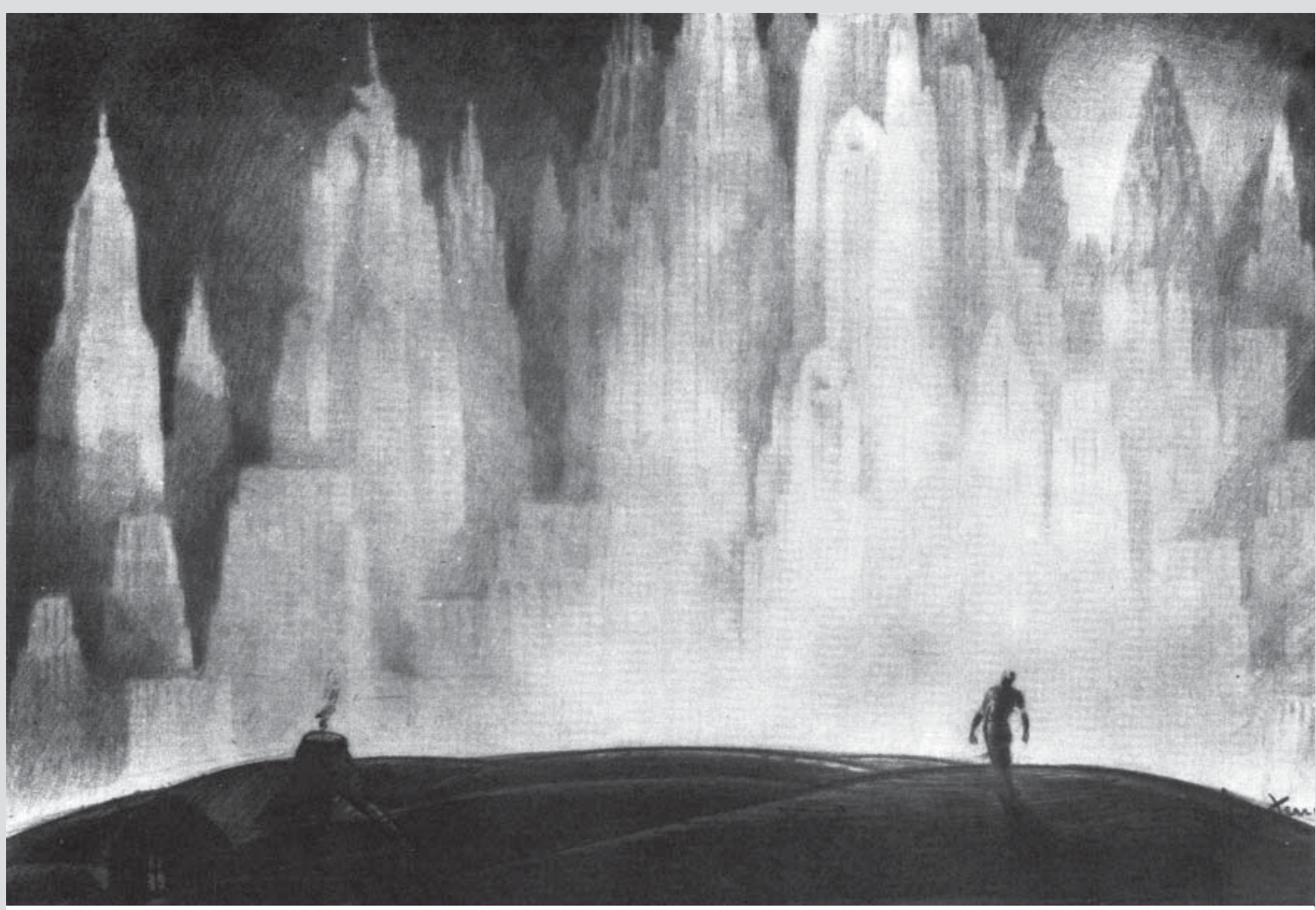

14. HUGH FERRISS, THE METROPOLIS OF TOMORROW, 1929, PÁGINAS INTERIORES.

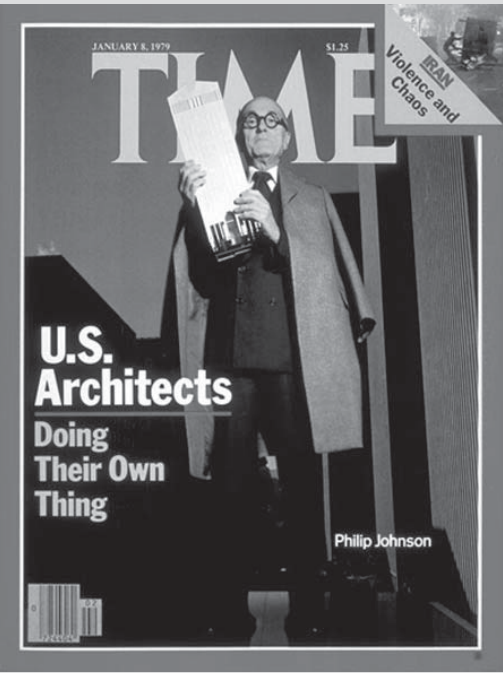


http://www.pritzkerprize. com/2OI3/jury-citation (I8/03/20I3)

Por otra parte, la arquitectura-espectáculo, al servicio de la affluent society y para su entertainment, adopta la corrección política y se viste de verde. Ito cuenta en su haber el proyecto de una especie de arca de Noé post-bíblica denominada Home-for-All, un espacio comunitario para supervivientes de grandes catástrofes ${ }^{74}$. El rey-arquitecto mesopotámico y el arquitecto-rey de nuestros días se ven a sí mismos comprometidos con la salvación de su pueblo. Pero sólo buscan su propia gloria.

\section{BIBLIOGRAFÍA}

ADAMS, R. McC. Heartland of Cities. Surveys of Ancient Settlement and Land Use on the Central Floodplain of the Euphrates, Chicago I98I.

BRAUN-HOLZINGER, E.A. Mesopotamische Weihgaben der frühdynastischen bis altbabylonischen Zeit, Heidelberg I99I.

BRETSCHNEIDER, J. / DRIESSEN, J. / LERBERGHE, K. van (eds.), Power and Architecture. Monumental Public Architecture in the Bronze Age Near East and Aegean, Leuven / Paris / Dudley, Ma 2007.

DULAU, R. / MORY, P. (eds.), Torresy rascacielos: De Babel a Dubái, Fundación "la Caixa”, Barcelona 2012 .

HEINRICH, E. Paläste im Alten Mesopotamien (Deutsches Archäologisches Institut: Denkmäler antiker Architektur 15), Berlin I984.

KÄMMERER, T. / METZLER, K.A., Das babylonische Weltschöpfungsepos 'Enūma elîsh', Münster $20 \mathrm{I2}$.

McMAHON, A. "Space, Sound, and Light: Toward a Sensory Experience of Ancient Monumental Architecture", American Journal of Archaeology 117, 2013, pp. I63-I79.

NEUMANN, H. / PAULUS, S. (eds.), Wissenskultur im Alten Orient. Weltanschauung, Wissenschaften, Techniken, Technologien, Wiesbaden 2012.

NIETZSCHE, F. Vom Nutzen und Nachteil der Historie für das Leben, Werke in drei Bänden, herausgegeben von K. Schlechta, vol. I, München I969.

NISSEN, H. Grundzüge einer Geschichte der Frühzeit des Vorderen Orients, Darmstadt I983.

PEDDE, B. "Das ,Neue Babylon"', Alter Orient aktuell 2, 200I, pp. 8-I2.

RÖMER, W.H.Ph. Sumerische 'Königshymnen' der Isin-Zeit, Leiden I965.

SANMARTÍN, J. Códigos legales de tradición babilónica, Madrid / Barcelona I999.

SANMARTÍN, J. Epopeya de Gilgamesh, rey de Uruk, Madrid 20 Io.

SEUX, M.-J. Épithètes Royales Akkadiennes et Sumériennes, Paris 1967.

SLOTERDIJK, P. Sphären II. Globen, Frankfurt am Main I999.

SMITH, M. (ed.), The Social Construction of Ancient Cities, Washington 2003.

STEINKELLER, P. "On Rulers, Priests and Sacred Marriage: Tracing the Evolution of Early Sumerian Kingship", in: K. Watanabe (ed.), Priests and Officials in the Ancient Near East, Heidelberg I999, p. IO3-I37.

STRECK, P. (ed.), Reallexikon der Assyriologie und Vorderasiatischen Archäologie, Band 13, Berlin / Boston 20 II.

WILHELM, G. (ed.), Die orientalische Stadt. Kontinuität, Wandel, Bruch, Berlin I997.

WILKE, G. "Zum Königtum in der Ur III-Zeit", en: P. Garelli (ed.), Le Palais et la royauté: Archéologie et civilisation. XIXe Rencontre Assyriologique Internationale [...] Paris 1971, Paris 1974, p. I79.

WIGGERMANN, F.A.M. Mesopotamian Protective Spirits: The Ritual Texts, Groningen I962. 